\title{
Pooled Analysis of external-beam RADiotherapy parameters in phase II and phase III trials in radiochemotherapy in Anal Cancer (PARADAC).
}

Eleonor Rivin del Campo ${ }^{1}$, Oscar Matzinger ${ }^{2}$, Karin Haustermans ${ }^{3}$, Didier Peiffert ${ }^{4}$, Robert Glynne-Jones ${ }^{5}$, Kathryn A. Winter ${ }^{6}$, Andre A. Konski ${ }^{7}$, Jaffer A. Ajani $^{8}$, Jean-François Bosset ${ }^{9}$, Jean-Michel Hannoun-Levi ${ }^{10}$, Marc Puyraveau ${ }^{11}$, A. Bapsi Chakravarthy ${ }^{12}$, Helen Meadows ${ }^{13}$, John Northover ${ }^{14}$, Laurence Collette $^{15}$, Melissa Christiaens ${ }^{3}$, Philippe Maingon ${ }^{16}$.

Department of Radiation Oncology, Tenon University Hospital, Sorbonne University, Paris, France.

Department of Radiation Oncology, Genolier Clinic, Genolier, Switzerland.

Department of Radiation Oncology, UZ Leuven University Hospital, Leuven, Belgium.

Department of Radiation Oncology, Institut de Cancérologie de Lorraine, Nancy, France.

Department of Radiation Oncology, Mount Vernon Cancer Centre, Northwood, United Kingdom.

'NRG Oncology Statistics and Data Management Center, American College of Radiology, Philadelphia, Pennsylvania, United States of America.

Department of Radiation Oncology, University of Pennsylvania Perelman School of Medicine. Leonard Davis Institute of Health Economics. Department of Radiation Oncology The Chester County Hospital, West Chester, Pennsylvania, United States of America.

Department of Radiation Oncology, MD Anderson Cancer Center, Houston, Texas, United States of America.

Department of Radiation Oncology, Jean Minjoz University Hospital, Besançon, France.

${ }^{10}$ Department of Radiation Oncology, Centre Antoine Lacassagne, Nice, France.

"Department of Statistics, Jean Minjoz University Hospital, Besançon, France.

"2 Department of Radiation Oncology, Vanderbilt University Medical Center, Nashville, Tennessee, United States of America.

${ }^{13}$ Cancer Research UK \& UCL Cancer Trials Centre, London, United Kingdom.

${ }^{14}$ Department of Surgery, The London Clinic and St Marks Hospital, London, United Kingdom.

is Department of Statistics, EORTC headquarters, Brussels, Belgium.

${ }^{16}$ Department of Radiation Oncology, La Pitié Salpêtrière - Charles Foix University Hospital, Sorbonne University, Paris, France.

Acknowledgments of research support for the study: The Kom Op Tegen Kanker supported the development of this project through the "Emmanuel van der Schueren Fellowship for Quality Assurance in Radiotherapy" EORTC fellow grants (Oscar Matzinger, Melissa Christiaens). UK Co-ordinating Committee for Cancer Research (UKCCCR), Radiation Therapy Oncology Group (RTOG), French Federation Nationale des Centres de Lutte Contre le Cancer (FNLCC), European Organization for the Research and Treatment of Cancer (EORTC) and the ECOG-ACRIN Cancer Research Group (ECOG-ACRIN). ECOG-ACRIN grants CA180820 and CA233270.

Corresponding author: Eleonor Rivin del Campo, $\mathrm{MD}, \mathrm{PhD}$

Department of Radiation Oncology,

Tenon University Hospital- Hôpitaux Universitaires Est Parisien, Sorbonne University

4 rue de la Chine, 75020 , Paris, France

Ph.: (33) 156016210 ; FAX: (33) 156016599

Email: eleonor.rivindelcampo@aphp.fr

Running head: PARADAC - Meta-analysis: radiotherapy parameters in anal cancer

The study has been presented in part in The European Cancer Congress 2013, September 27 $7^{\text {th }}$ October $1^{\text {st }} 2013$ (Amsterdam).

Disclaimers: None 


\section{Abstract}

PURPOSE: Concomitant external-beam radiochemotherapy (5-Fluorouracil-Mitomycin C) has become the standard of care in anal cancer since the '90s. A pooled analysis of individual patient data from 7 major trials was performed quantifying the effect of RTrelated parameters on the outcome of patients with anal cancer.

MATERIALS AND METHODS: Pooling databases from combined modality trials, the impact of RT parameters (total dose, gap duration, OTT: overall treatment time) on outcome including locoregional failure (LRF), 5-year progression-free-survival (PFS) and toxicities were investigated. Individual patient data was received for 10/13 identified published studies conducted from 19872008(n=3031). A Cox-regression model was used (landmark=3 months post-RT for first follow-up).

RESULTS: After data inspection indicating severe heterogeneity between trials, only 1343 patients from the 7 most recent studies (since 1994) were analyzed (median follow-up=4.1 years). A higher overall 5-year LRF rate [22.8\% (95\%CI 22.3-27.3\%)] significantly correlated with longer OTT $(\mathrm{p}=0.03)$, larger tumor size $(\mathrm{p}<0.001)$ and borderline significantly with male gender $(\mathrm{p}=0.045)$. Though significant differences were not observed, subset analyses for LRF (dose range:50.4-59Gy) seemed to favor lower doses $(\mathrm{p}=0.412)$, and when comparing a 2 week gap versus 3 (dose:59.4Gy), results suggested 3 weeks might be detrimental $(\mathrm{p}=0.245)$. For a 2 week gap versus none (dose range:55-59.4Gy) no difference was observed ( $\mathrm{p}=0.89$ ). Five-year PFS was $65.7 \%$ (95\%CI: 62.8-68.5\%)]. Higher PFS rates were observed in women $(\mathrm{p}<0.001)$, smaller tumor sizes $(\mathrm{p}<0.001)$ and shorter OTT 
$(p=0.025)$. Five-year OS [76.7\%(95\%CI: 73.9\%-79.3\%)] correlated with female gender $(p<0.001)$, small tumor size $(p=0.027)$ and short OTT $(\mathrm{p}=0.026)$. Descriptive toxicity data is presented.

CONCLUSION: For patients receiving concurrent external-beam doublet chemoradiation a longer OTT seems detrimental to outcome. Further trials involving modern techniques may better define optimal OTT and total dose. 


\section{Pooled Analysis of external-beam RADiotherapy parameters in phase II and phase III trials in Anal Cancer (PARADAC).}

\section{Introduction}

Anal cancer is a rare tumor arising from the gastrointestinal tract. Over the past decades an increase in incidence has been observed for in situ and squamous cell anal carcinoma ${ }^{1,2}$. The most important risk factors are: previous gynaecological or blood related cancer, smoking, sexually transmitted diseases (HPV, HIV, herpes, etc.), sexual partners exceeding 10, long-term immunosuppression and receptive anal intercourse ${ }^{2}$.

Until the seventies abdominoperineal resection remained the standard of care, with an operative mortality rate of about 6-8 percent $^{3}$. Five-year overall survival (OS) rates of 40 to $70 \%$ were reported, with 5 -year recurrence rates of approximately $40 \%{ }^{4,5}$. After radiation therapy (RT), whether or not followed by surgery, similar disappointing results were reported ${ }^{4}$. The concomitant use of chemotherapy, 5-Fluorouracil (5-FU) with Mitomycin C (MMC), with usually split course RT dramatically improved local control (LC) and colostomy free survival (CFS). Thus, radical surgery was replaced with primary chemoradiation as the standard of care ${ }^{3,6,7 .}$ Almost two thirds of patients could be cured and their sphincter preserved with this approach ${ }^{3,6,7}$. Nevertheless, the prognosis remained poor for patients with advanced disease or lymph node involvement. Despite attempts to improve on this treatment, the standard treatment for locally advanced disease remained unchanged for years with the most recent contributions confirming the 
efficicacy of RT with 5-FU and $\mathrm{MMC}^{7-10}$. The most concrete improvement in the treatment of this disease is the introduction of new modalities of RT delivery, Intensity Modulated Radiation Therapy (IMRT) and Volumetric Modulated Arc Therapy (VMAT), allowing a better toxicity profile with comparable outcomes ${ }^{11-16}$. However, many questions remain a matter of debate.

A pooled analysis of individual patient data from 7 major prospective trials was performed with the aim to quantify the effect of RT-related parameters on the outcome of patients with anal cancer to improve guidelines for future RT combined modality studies.

\section{Materials and methods}

\section{Selection criteria:}

A consensus meeting was held at the European Organization for the Research and Treatment of Cancer (EORTC) Headquarters on March $6^{\text {th }}$, 2008, with representatives of European countries and collaborative groups active in the field of radiochemotherapy for advanced anal cancer: the Italian group, Spanish Group, Nordic Group, UK Co-ordinating Committee for Cancer Research (UKCCR) and the French Federation Nationale des Centres de Lutte Contre le Cancer (FNCLCC). The aim of the meeting was to agree on the design of the next phase III randomized trial testing improved radio-therapeutic regimes. To prepare, the group reviewed available evidence from phase II and III studies for anal cancer, including the then recently closed phase III trials, such as ACCORD-03 ${ }^{17}$. The studies identified at the time are detailed in Table 1. 
Table 1. Phase II and III studies in anal cancer. Individual patient data was received for all studies in bold.

\begin{tabular}{|c|c|c|c|c|c|c|c|c|c|c|c|c|c|c|}
\hline Group & $\begin{array}{l}\text { Study } \\
\text { Name }\end{array}$ & Phase & $\begin{array}{c}\text { No. } \\
\text { Patients }\end{array}$ & $\begin{array}{l}\text { No. eligible } \\
\text { patients }\end{array}$ & Inclusion Stage & $\begin{array}{l}\text { No. } \\
\text { N0/N1 }\end{array}$ & NACT & Concurrent CT & $\begin{array}{c}\text { Consolidation } \\
\text { CT }\end{array}$ & $\begin{array}{l}\text { Pelvic Dose } \\
\text { (Gy)/fr. }{ }^{\top}\end{array}$ & Boost Dose(Gy)/fr. & $\begin{array}{l}\text { Inguinal } \\
\text { Dose (Gy) }\end{array}$ & $\begin{array}{l}\text { Inguinal. dose } \\
\mathrm{N}+\text { (Gy) }\end{array}$ & $\begin{array}{c}\text { Gap } \\
\text { (weeks) }\end{array}$ \\
\hline \multirow[t]{3}{*}{ EORTC } & $22861^{6}$ & III & 110 & 103 & $\begin{array}{c}\text { All } \mathrm{T}>4 \mathrm{~cm} \text { and/or } \\
\text { all } \mathrm{N}+; \mathrm{MO}\end{array}$ & $57 / 53$ & No & \pm 5 -FU - MMC & No & $45 / 25$ & $\begin{array}{c}15 \text { if } \mathrm{CR} \\
20 \text { if } \mathrm{PR} \\
\mathrm{EBRT} \text { or } \mathrm{BT}\end{array}$ & 0 & $45+15 / 20$ & 6 \\
\hline & $22953^{18}$ & II & 44 & 43 & $\begin{array}{c}\text { All } \mathrm{T}>4 \mathrm{~cm} \text { and/or } \\
\text { all } \mathrm{N}+; \mathrm{MO}\end{array}$ & $25 / 18$ & No & \pm 5 -FU - MMC & No & $36 / 20$ & $\begin{array}{c}23.4 / 13 \\
\text { EBRT or BT }\end{array}$ & 0 & 59.4 & 2 \\
\hline & $\mathbf{2 2 0 1 1}^{19}$ & II & 88 & 76 & $\begin{array}{c}\text { All T }>4 \mathrm{~cm} \text { and/or } \\
\text { all } \mathrm{N}+; \mathrm{MO}\end{array}$ & $50 / 38$ & No & $\begin{array}{l}\text { 5-FU - MMC vs. } \\
\text { Cisplatin - MMC }\end{array}$ & No & $36 / 20$ & $\begin{array}{c}23.4 / 13 \\
\text { EBRT or BT }\end{array}$ & 0 & $36+$ surgery & 2 \\
\hline \multirow[t]{3}{*}{ UKCCCR } & ACT $\mathbf{I}^{20,21}$ & III & 585 & 577 & All (except T1N0); M0 & $\begin{array}{c}c N+: 31 \\
\text { pts }\end{array}$ & No & \pm 5 -FU - MMC & No & $45 / 20$ or 25 & $\begin{array}{c}15 / 6 \text { EBRT or } \\
25 \mathrm{~Gy}: 10 \mathrm{~Gy} / \mathrm{day}, \mathrm{BT} \\
\text { if } \mathrm{R}>50 \%\end{array}$ & \pm 45 & - & 6 \\
\hline & EXTRA $^{22}$ & II & 31 & 31 & All & $23 / 8$ & No & $\begin{array}{l}\text { Capecitabine - } \\
\text { MMC }\end{array}$ & No & $30.6 / 17$ & 19.8/11 & 30.6 & 50.4 & 0 \\
\hline & ACT $\|^{9}$ & III & 940 & 935 & All; MO & $609 / 302$ & No & $\begin{array}{l}\text { 5-FU - MMC vs. } \\
\text { 5-FU - Cisplatin }\end{array}$ & $\begin{array}{c} \pm 2 \text { cycles } \\
5 \text {-FU-Cisplatin }\end{array}$ & $30.6 / 17$ & 19.8/11 & 30.6 & 50.4 & 0 \\
\hline \multirow{3}{*}{ RTOG } & $87-04^{23}$ & III & 310 & 289 & All T \& N; MO & $240 / 51$ & No & $5-\mathrm{FU} \pm \mathrm{MMC}$ & No & $45 / 25^{+}$ & $5.4 / 3$ & 45 & 50.4 & 0 \\
\hline & $92-08^{24}$ & II & 46 and 20 & 66 & All $T>2$ cm; MO & $41 / 6$ & No & 5-FU - MMC & No & $45 / 25^{\ddagger}$ & $14.4 / 8$ & 45 & 59.4 & 2 and 0 \\
\hline & $98-11^{8,25}$ & III & 682 & 638 & All except T1; M0 & $448 / 196$ & $\begin{array}{l} \pm 5 \text {-FU - } \\
\text { Cisplatin }\end{array}$ & $\begin{array}{l}\text { 5-FU - MMC vs. } \\
\text { 5-FU - Cisplatin }\end{array}$ & No & $45 / 25$ & $10-14 / 5-7$ & 45 & $55-59$ & 0 \\
\hline \multirow[t]{2}{*}{ FNLCC } & $26 * \star$ & II & 80 & 80 & $\begin{array}{c}T>4 \mathrm{~cm} \text { and/or } \\
\mathrm{N+}, \mathrm{MO}\end{array}$ & $18 / 62$ & $\begin{array}{l}\text { 5-FU- } \\
\text { Cisplatin }\end{array}$ & 5-FU - Cisplatin & No & $45 / 25$ & $\begin{aligned} & 15 \text { if } \mathrm{CR} \\
& 20 \text { if } \mathrm{PR} \\
& \text { EBRT or } \mathrm{BT}\end{aligned}$ & 0 & $60-65$ & $4-8$ \\
\hline & $\begin{array}{l}\text { ACCORD } \\
-03^{17 * \star}\end{array}$ & III & 307 & 307 & $\begin{array}{c}\text { All T }>4 \mathrm{~cm} \text { and/or } \\
\text { all } \mathrm{N}_{+} ; \mathrm{MO}\end{array}$ & $182 / 120$ & $\begin{array}{l} \pm 5 \text {-FU- } \\
\text { Cisplatin }\end{array}$ & 5-FU - Cisplatin & No & $45 / 25$ & $\begin{array}{c}15 \text { or } \\
20-25(20 \text { if } R>80 \%) \\
\text { EBRT or } B T\end{array}$ & \pm 45 & $\begin{array}{l}\text { surgery }+45 \\
\text { or } 60-65\end{array}$ & 3 \\
\hline $\begin{array}{l}\text { ECOG- } \\
\text { ACRIN }\end{array}$ & $42-92^{27}$ & II & 32 & 32 & All; MO & $17 / 12$ & No & 5-FU - Cisplatin & No & $45 / 25^{x}$ & $14.4 / 8$ & 36 & 59.4 & 2 \\
\hline CALGB & $9281^{28}$ & II & 45 & 45 & $\begin{array}{c}\text { T3 }>5 \mathrm{~cm} ; \mathrm{T} 4 \text { and all } \\
\mathrm{N+}\end{array}$ & - & $\begin{array}{l}\text { 5-FU - } \\
\text { Cisplatin }\end{array}$ & 5-FU - MMC & $\begin{array}{l}\text { 5-FU-Cisplatin } \\
\text { if PR or N2/N3 }\end{array}$ & $45 / 25^{\ddagger}$ & $14.4 / 8$ & 30.6 & 50.4 & 2 \\
\hline
\end{tabular}

* No. of eligible patients with analyzable data

** published in 2012, ongoing at the time of the meeting

$\overline{\mathbf{T}}_{\text {in }}$ fractions of $1.8 \mathrm{~Gy}$ for all studies, except for ACT 1 in fractions of $1.8 \mathrm{~Gy}$ or $2.25 \mathrm{~Gy}$. RTOG 98-11 advises the boost to be given in fractions of $2 \mathrm{~Gy}$.

${ }^{+}$field reduction at $30.6 \mathrm{~Gy}$ and at $36 \mathrm{~Gy}$. If after the full treatment there was a residual histologically confirmed primary or inguinal lymph node, addition of a second boost ( 9 Gy).

$\ddagger$ field reduction at $30.6 \mathrm{~Gy}$.

$\times$ field reduction at 30.6 Gy and at 36 Gy.

Abbreviations: No., number; Gy, NACT, neoadjuvant chemotherapy; CT, chemotherapy; fr., fractions; Gy, Gray; EORTC, European Organization for the Research and Treatment of Cancer; UKCCCR, UK Co-ordinating Committee for Cancer Research; RTOG, Radiation Therapy Oncology Group; FNCLCC, French Federation Nationale des Centres de Lutte Contre le Cancer; ECOG-ACRIN, ECOG-ACRIN Cancer Research Group; CALGB, Cancer and Leukemia Group B; 5-FU, 5-fluouracil; MMC, Mitomycin C; CR, complete response; PR, partial response; el., electrons; ph., photons; BT, brachytherapy; R > 50\%, response > 50\%; EBRT, external beam radiotherapy. 
Studies:

ACCORD-03, examined the impact of therapeutic intensification by induction chemotherapy and/or high dose $\mathrm{RT}^{17}$. Several studies (EORTC 22011, RTOG 98-11 and ACT II) evaluated the feasibility of different chemotherapy schemes in combination with RT, with or without induction or maintenance chemotherapy ${ }^{8,9,19,25}$. The EORTC 22953 trial investigated the effect of a reduction of the gap (16-days) in combination RT and 5-FU-MMC treatment for anal cancer versus a standard 6 weeks gap ${ }^{18}$. In the UKCCCR EXTRA trial intravenous 5-FU was replaced by Capecitabine ${ }^{22}$. ECOG-ACRIN 42-92 studied the feasibility of Cisplatin replacing MMC with a 2 week gap ${ }^{28}$.

A consensus emerged that it was not timely to start a new trial, given the number of existing projects in the various countries that were still maturing at the time, and the difficulty to finance such academic trials. Considering the rarity of the disease, an international European or worldwide collaboration was needed for a successful phase III study.

A proposal was made for pooling databases from existing trials to explore the impact of specific RT parameters and toxicities on outcome. It was acknowledged that to address these questions would entail between-trial protocol comparisons. The questions that emerged revolved around the impact of overall treatment time (OTT, affected by the duration of the gap) and RT dose on local recurrence. The relationship between irradiated pelvic volume and pelvic recurrence rates, the total dose to the elective inguinal area and inguinal control, long term toxicity related to irradiated volume/total dose and of prognostic factors for long term outcome in relation with the baseline patient and disease characteristics was assessed. 
Data collection and extraction:

For each included study, the protocol and publication of results were obtained. The following individual patient data were requested for each patient:

- Patient-related: Age; gender; date of entry/randomization.

- Tumor-related: Date of diagnosis; cT; cN; cM; maximum tumor size; tumor localization (i.e. anal margin involved); inguinal node involvement (if involved, number and size); pelvic nodal involvement (if involved, number and size).

- Treatment-related: Treatment arm; RT parameters [date of start, total dose to the primary tumor (number of fractions), total dose to positive lymph nodes (number of fractions), total dose to the elective pelvic area (number of fractions), Total dose to the elective inguinal area (number of fractions), OTT (tumor; positive nodes; elective), gap duration]; chemotherapy (if given, date of start, drugs used (5-FU, MMC, Cisplatin, other).

- Outcomes: Last follow up date; survival status; local recurrence and date (if any); pelvic recurrence status and date; inguinal recurrence status and date; distant recurrence status and date; date of colostomy (if performed); date of lymph node resection and procedure (if performed).

- Late Toxicity: Bladder; bone; skin; intestine; anus (worst grade, date of start, scale).

No specific format for data collection was specified. Since many trials were historical, not all data could be obtained for all studies, depending on the data collection system used (see results). 


\section{Statistical analysis:}

Recognizing that treatment effects of interest in the analysis required assessments across studies, but were essentially fixed by each trial protocol, a Cox model was developed to adjust for patient specific factors in a subgroup of the data selected to minimize systematic heterogeneity due to protocol specific criteria (e.g. eligibility criteria) and included factors representing RT dose and OTT. The model included adjustment for age (continuous linear effect), gender, tumor localization (anal margin, anal canal or both), $\mathrm{N}$ stage (pelvic $\mathrm{N} 0 / \mathrm{N}+$ without inguinal involvement/ pelvic $\mathrm{N}+$ with inguinal involvement/ pelvic $\mathrm{N}+$ with unknown inguinal status) and tumor size within $\mathrm{N}$ categories within tumor location. The latter was to accommodate for interaction effects and to fulfill the proportional of hazard assumptions. The OTT was modelled as a continuous effect, whereas the total dose was assessed in categories ( $\leq 50.5 \mathrm{~Gy},>50.5$ to $55 \mathrm{~Gy},>55$ to $59 \mathrm{~Gy},>59$ to $59.4 \mathrm{~Gy}$ and $>59.4 \mathrm{~Gy}$ ). The categories were created to accommodate the intrinsically discrete set of total doses planned in the study protocols (Appendix A: Figure 1). 
Appendix A. Figure 1. Overall treatment time according to the total dose to the anal canal. Online only.

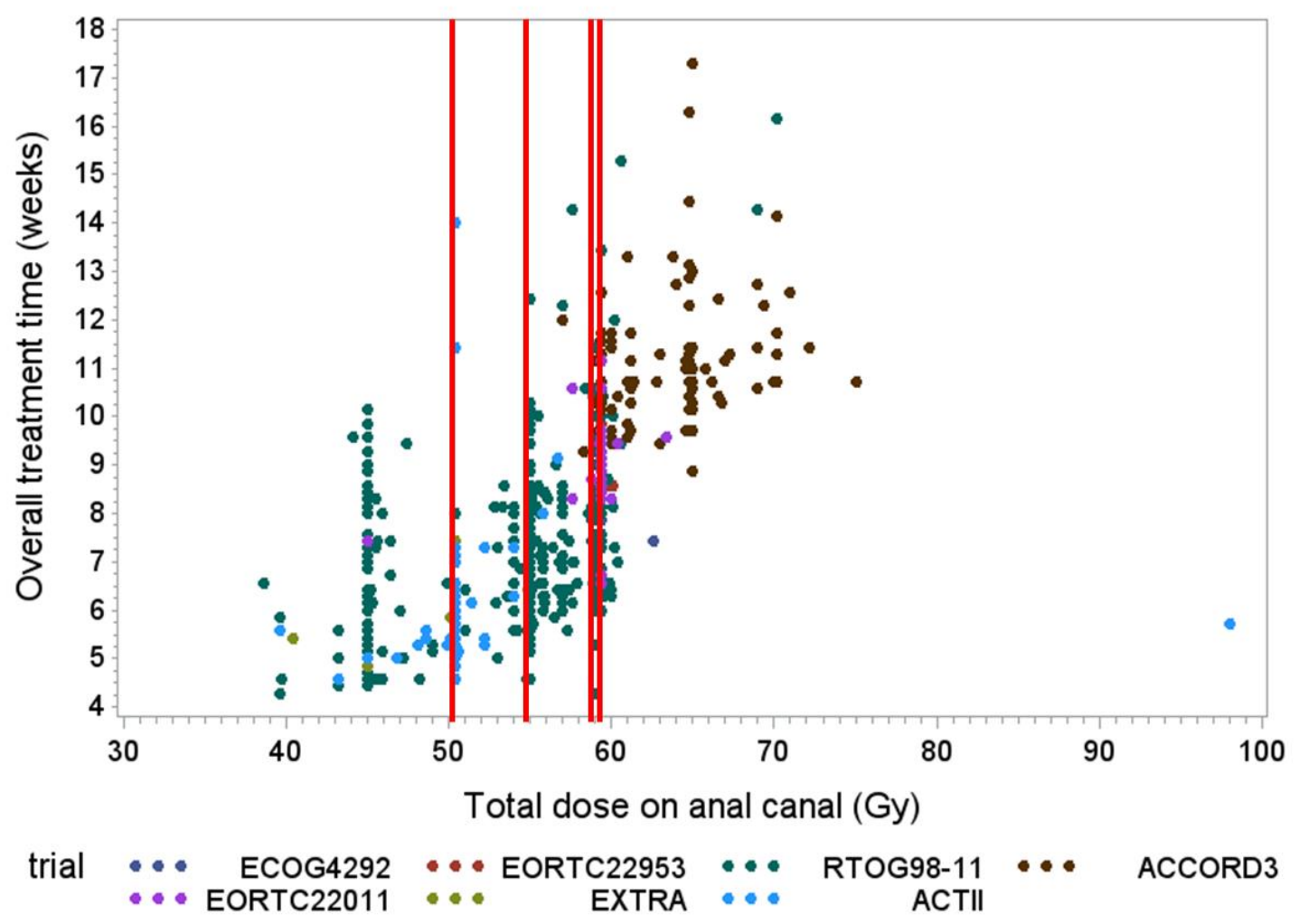

For the analysis of locoregional failure (LRF), our primary endpoint, a landmark of 3 months was used to homogenize the timing of first disease assessment during follow-up in the studies, and the time was censored at 5 years to harmonize the duration of follow-up.

The adequacy of the Cox regression model was evaluated by performing the graphical and numerical methods of Lin, Wei and Ying ${ }^{29}$. Based on intermediate study results that showed a single model could not fit the early trials that used RT alone \pm one chemotherapeutic drug and the more recent studies that used RT \pm a doublet of drugs, the primary analysis set was restricted to patients treated with doublet chemotherapy after 01/01/1994.

The analysis was exploratory and two-sided tests were used with a 5\% significance level. 


\section{Results}

Merging data

Data was provided by $10 / 13$ trials, amounting to 3031 patients. Assessment of data received and of study protocols revealed severe heterogeneity in patient selection criteria, the staging system used and the capture of the RT treatment data. An attempt was made to harmonize the data from the trials, to allow merging of the databases while excluding as few patients as possible (Figure 1).

Patients were recruited during a two decade period (1987-2008) (Appendix A, figure 2). The difference in terms of data collection, patient staging, treatments and patient follow-up was particularly evident between the first 3 trials (EORTC 22861, ACT I and RTOG 87-04), conducted with $\mathrm{RT} \pm$ two chemotherapeutic drugs $(\mathrm{RT}+$ single or doublet chemotherapy for the RTOG trial), and the later trials which assessed RT + doublet chemotherapy $(\mathrm{RT} \pm$ doublet chemotherapy for the EORTC 22953 trial) ${ }^{6,20,21,23}$. Heterogeneity was such that no model could fit both groups of studies together. Since current treatment involves doublet chemotherapy with RT, the analysis was restricted to the more recent studies (Figure 1; Appendix A, figure 2).

Certain parameters (e.g.: planned RT dose, OTT) were specified inside a trial, but varied between trials. Thus it was essential to minimize any systematic differences in other factors that would also be confounded with the trial effect in our models. We assessed the eligibility criteria of the studies and selected patients for the analysis fitting the most stringent criteria across protocols, excluding patients $>75$ years or patients with unknown age, T1N0 and M1 or Mx disease from the analysis.

For many patients important data [e.g. N-stage, dose to the anal canal, OTT, tumor localization, gap duration, total dose to the pelvis, etc.] could not be retrieved or derived. In 
particular, OTT and total dose could not be calculated for patients who received brachytherapy. Since these factors were key to the analysis, these patients were excluded. Also, very short treatment times ( $<30$ days) or very low dose $(<36 \mathrm{~Gy})$ could result from excess toxicity or very poor prognosis or performance status (30 patients) or from protocol planned dose adaptations triggered by intermediate assessment of the response to treatment (21 patients). We applied a landmark of 90 days to not overestimate the association between treatment and outcome (due to the exclusion of the 21 patients during the landmark) and harmonize the timing of the first visit in the studies.

Toxicity was also scored heterogeneously between trials. Some trials systematically reported late toxic events at each follow-up, whereas others only reported one event (the worst grade) per patient in the received data files. The scales used for grading were also very heterogeneous (RTOG/EORTC, SOMA-LENT, NCI CTC different versions) (Appendix A. Table 1). A common scale for toxicity was applied and was based on the 'RTOG/EORTC Late RT Morbidity Scoring Scheme' as it was the most used. The toxicities were classified into groups and scored into mild/moderate vs. severe). Late toxicity was considered as starting more than 90 days after the start of treatment.

\section{Results pooled analysis:}

A total of 1343/3031 patients were eligible for the pooled analysis (Figure 1). Their characteristics and RT-related parameters are presented in Table 2. The overall median duration of follow-up within these trials was 4.1 years (Appendix A: Figure 3).

In total, 419 patients (31.2\%) developed clinical failure during follow-up (local, inguinal or locoregional relapse, distant metastases or death). 
An inguinal recurrence was recorded in 4 studies (ACCORD-03, EORTC 22011, EXTRA and ACT II), occurring in 54 of the 741 patients evaluable in these studies (7.3\%). At treatment initiation; 21 of the 54 patients had N0 disease, while 33 had positive nodes, of which 6 had no positive inguinal nodes.

LRF was described in 295 patients (22\%). LRF was defined as a local recurrence, a regional recurrence or local surgery (abdominoperineal resection or colostomy). The 5-year cumulative rate of LRF was 22.8\% [(95\%CI 22.3-27.3\%) Figure 2]. Lymph node resection surgery was not considered as an event (this data was only available on the 3 EORTC trials, only 3 patients had a lymph node resection before documented LFR).

LRF was significantly correlated with OTT $(\mathrm{p}=0.03)$, tumor size $(\mathrm{p}<0.001)$ and borderline significantly associated with gender $(\mathrm{p}=0.045)$. OTT and total dose were not markedly different between males and females (Appendix A: Table 2).

As the dose and the gap duration were very closely related by design of the protocols with the lowest (50.4 Gy, except for the good prognosis patients in RTOG) and intermediate doses (55-59 Gy) given without a gap and the higher doses ( $\geq 59.4$ Gy) given with a 2 or 3 week gap, no model was able to study the effect of the dose and the gap duration separately. A comparison between the lower and intermediate doses, without a gap, could be made. To avoid bias in favor of low doses, N0 patients treated at 45Gy were excluded. Only patients from the RTOG 98-11 treated at intermediate doses versus patients treated in ACT II and EXTRA at a planned dose of 50.4Gy were considered in this analysis (also adjusted for gender, age, tumor location, N-stage and tumor size). Based on 220 locoregional relapse events (n=977), no difference between dose levels could be seen. However, results seemed to favor a lower dose (Appendix A: Table 3). To assess the impact of the gap duration, we compared patients intended 
to receive a dose of $59.4 \mathrm{~Gy}$ with either a 2 week gap versus a 3 week gap (i.e. patients in EORTC studies versus ACCORD-03 arms 1 and 3). In this group of 232 patients 68 locoregional relapses were registered. The analysis suggests that a 3 week gap might be detrimental, although the effect was not statistically significant (Appendix A: Table 4)

A 2 week gap was compared to no gap in patients who were intended to receive a dose of 55 to 59.4Gy (EORTC studies versus RTOG 98-11). In this group, 113 events were observed among 521 patients. A supplementary sensitivity analysis was performed in this group by restricting the analysis to patients who had effectively received a dose of $>56.5 \mathrm{~Gy}$ and <60.0Gy $(n=214)$. Only 74 events were seen. Neither analysis showed a significant difference between a 2-week gap and no gap (Appendix A: Table 5).

The 5-year progression free survival (PFS) rate was $65.7 \%$ (95\% CI: 62.8-68.5\%). The occurrence of a clinical event was less frequent in women $(\mathrm{p}<0.001)$ or in patients with small tumor size $(\mathrm{p}<0.001)$ or shorter OTT $(\mathrm{p}=0.025)$. The 5-year OS was $76.7 \%$ (95\% CI: 73.9\%$79.3 \%)$ and it correlated with gender $(\mathrm{P}<0.001)$, with a higher OS for women, small tumor size $(\mathrm{p}=0.027)$ and short OTT $(\mathrm{p}=0.026)$ (Figure 2, Appendix A: Table 2).

Late toxicities (90 days or more from the start of treatment), were divided into gastrointestinal, skin or subcutaneous tissue and bladder-genito-urinary late toxicities (Table 3). 
Figure 1: PRISMA flowchart of selection of eligible patients for the pooled analysis to get a more homogenous group of patients.

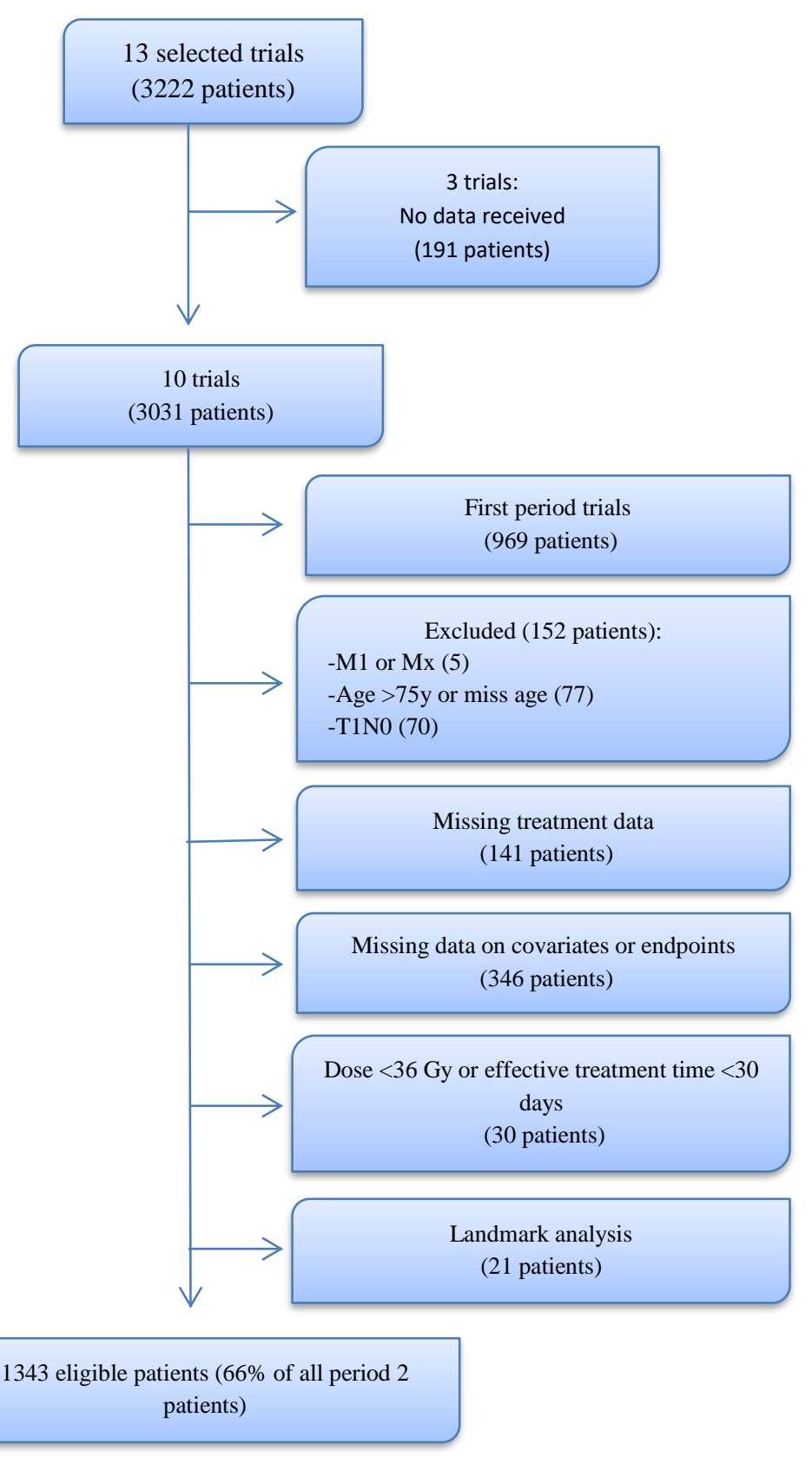


Appendix A. figure 2: Summary of Trials. $n=$ number of patients included in the final analysis per trial. Online only.

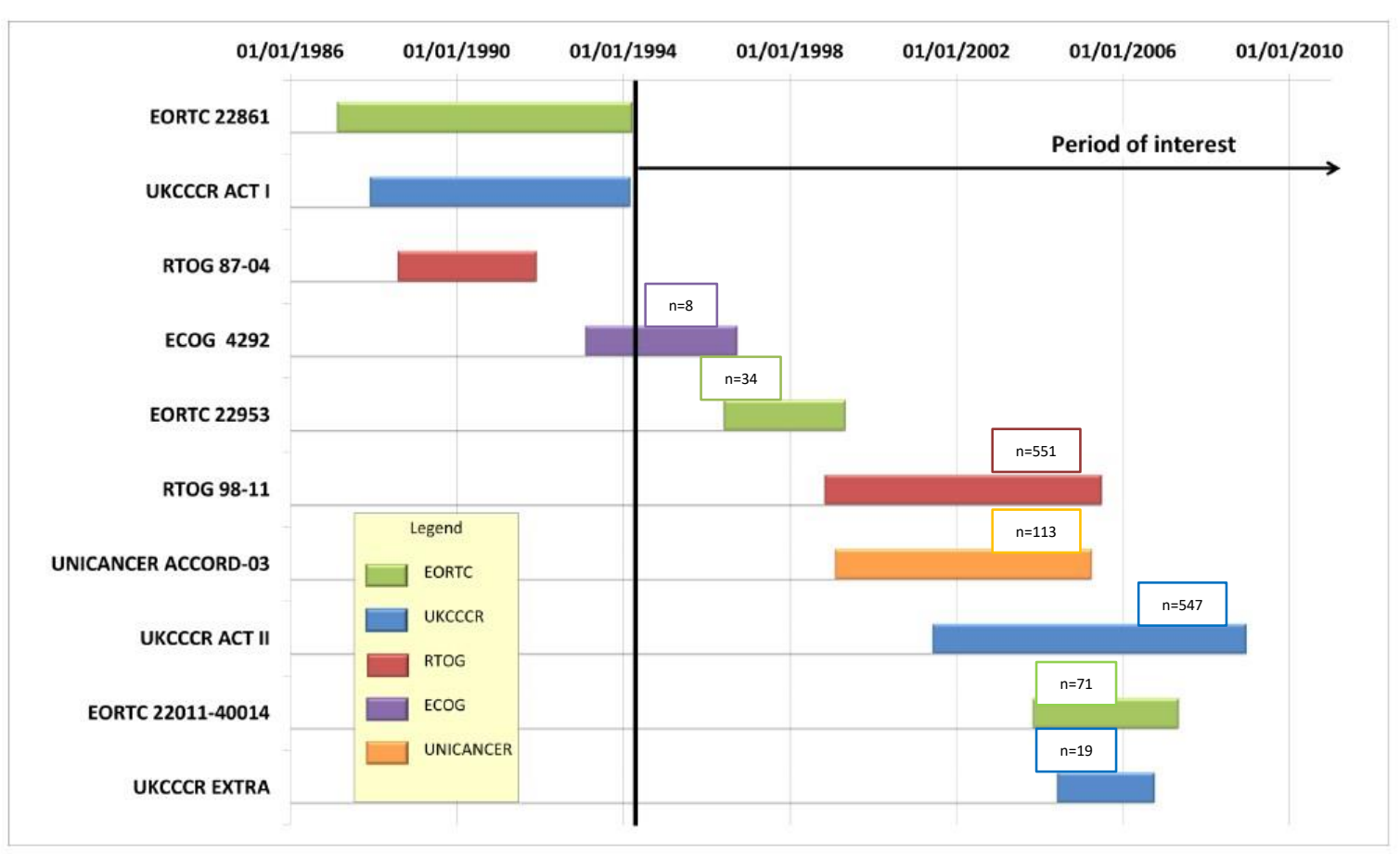




\section{Appendix A. Table 1. Evaluated toxicities and scales used for toxicity grading for the $\mathbf{1 0}$}

\section{trials data was received for. Online only.}

\begin{tabular}{|c|c|c|c|c|}
\hline Group & Study & Defined selected toxicities & Scale & Comment \\
\hline \multirow{3}{*}{ EORTC } & 22861 & $\begin{array}{l}\text { Rectal discharge } \\
\text { Rectal bleeding } \\
\text { Anal/rectal damage } \\
\text { Rectal stenosis } \\
\text { Rectal incontinence } \\
\text { Colostomy } \\
\text { Skin reaction } \\
\text { Fibrosis } \\
\text { Other }\end{array}$ & $\begin{array}{l}\text { RTOG/EORTC Late RT Morbidity Scoring Scheme (NCI CTC v2) scale } \\
\text { for skin reaction and sub tissue (fibrosis) } \\
\text { Study specific defined scales for the other categories }\end{array}$ & \\
\hline & 22953 & $\begin{array}{l}\text { Bladder/Urethra } \\
\text { Skin/subcutaneous tissue } \\
\text { Rectum } \\
\text { Small intestine / Colon }\end{array}$ & SOMA/LENT & \\
\hline & 22011 & $\begin{array}{l}\text { Bladder } \\
\text { Skin } \\
\text { Small/large intestine } \\
\text { Subcutaneous tissue } \\
\text { Other }\end{array}$ & RTOG/EORTC Late RT Morbidity Scoring Scheme (NCI CTC v2) & \\
\hline \multirow{3}{*}{ UKCCCR } & ACT 1 & $\begin{array}{l}\text { Ano-rectal } \\
\text { Skin } \\
\text { Hip/bone. }\end{array}$ & $\begin{array}{l}\text { No specified scale used, only refers to grade } 3 \text { or } 4 \text { toxicities without } \\
\text { specifying the exact grade }\end{array}$ & \\
\hline & EXTRA & $\begin{array}{l}\text { Skin } \\
\text { Large intestine } \\
\text { Rectal or perirectal pain Pain }\end{array}$ & $\begin{array}{l}\text { RTOG/EORTC Late RT Morbidity Scoring Scheme (NCI CTC v2) for } \\
\text { Skin and Large intestine, Renal / genitourinary and pain }\end{array}$ & $\begin{array}{l}\text { A lot of "other" } \\
\text { toxicities }\end{array}$ \\
\hline & ACT II & $\begin{array}{l}\text { due to radiation, Urinary } \\
\text { frequency/urgency } \\
\text { Other }\end{array}$ & Scales of NCI CTC v2 for the other toxicities & \\
\hline \multirow[b]{2}{*}{ RTOG } & $87-04$ & $\begin{array}{l}\text { Skin } \\
\text { Gastrointestinal } \\
\text { Genitourinary } \\
\text { Stomatitis/Mucus membrane } \\
\end{array}$ & RTOG/EORTC Late RT Morbidity Scoring Scheme (NCI CTC v2) & \\
\hline & $98-11$ & $\begin{array}{l}\text { Bladder } \\
\text { Skin } \\
\text { Small/large intestine } \\
\text { Subcutaneous tissue } \\
\text { Other } \\
\end{array}$ & RTOG/EORTC Late RT Morbidity Scoring Scheme (NCI CTC v2) & \\
\hline $\begin{array}{l}\text { ECOG- } \\
\text { ACRIN }\end{array}$ & $42-92$ & \multicolumn{3}{|c|}{ No late toxicities have been reported } \\
\hline FNCLCC & $\begin{array}{l}\text { ACCORD- } \\
03\end{array}$ & $\begin{array}{l}\text { Bladder/Urethra } \\
\text { Skin/subcutaneous tissue } \\
\text { Rectum } \\
\text { Small Intestine/Colon }\end{array}$ & SOMA/LENT & $\begin{array}{l}\text { Only some scales are } \\
\text { pre-specified }\end{array}$ \\
\hline
\end{tabular}


Table 2: Patient characteristics and radiotherapy-related parameters of the group of patients included in the pooled analysis.

\begin{tabular}{|c|c|}
\hline & $\begin{array}{c}\text { Total (N=1343) } \\
\text { N (\%) }\end{array}$ \\
\hline \multicolumn{2}{|l|}{ Age (years) } \\
\hline Median (range) & $56(25-75)$ \\
\hline Quartile1-Quartile3 (Q1-Q3) & $48-64$ \\
\hline & $55.1(9.92)$ \\
\hline Mean (SD) & \\
\hline \multicolumn{2}{|l|}{ Gender } \\
\hline Male & $449(33.4)$ \\
\hline Female & $894(66.6)$ \\
\hline \multicolumn{2}{|l|}{ Tumor localization } \\
\hline Anal margin & $82(6.1)$ \\
\hline Anal canal or both & 1261 (93.9) \\
\hline \multicolumn{2}{|l|}{ T stage } \\
\hline $\mathrm{T} 1$ & $23(1.7)$ \\
\hline $\mathrm{T} 2$ & $638(62.4)$ \\
\hline T3 & $296(22.0)$ \\
\hline T4 & $186(13.8)$ \\
\hline \multicolumn{2}{|l|}{ Max tumor size $(\mathrm{cm})$} \\
\hline Median (range) & $4.1(1-20)^{*}$ \\
\hline Q1-Q3 & $3.0-5.5$ \\
\hline Mean (SD) & $4.7(2.03)$ \\
\hline \multicolumn{2}{|l|}{$\mathrm{N}$ stage } \\
\hline NO & $865(64.4)$ \\
\hline $\mathrm{N}+$ without inguinal invasion $(\mathrm{N}+$ ing-) & $202(15)$ \\
\hline $\mathrm{N}+$ with inguinal invasion $(\mathrm{N}+$ ing+) & $144(10.7)$ \\
\hline $\mathrm{N}+$ with unknown inguinal status $(\mathrm{N}+$ ing?) & $132(9.8)$ \\
\hline \multicolumn{2}{|l|}{ Planned gap duration (days) } \\
\hline 0 & $1125(83.8)$ \\
\hline 14 & $105(7.8)$ \\
\hline 21 & $113(8.4)$ \\
\hline \multicolumn{2}{|l|}{ Effective duration of the gap (days) } \\
\hline Median (range) & $0(0-68)$ \\
\hline Q1-Q3 & $0-0$ \\
\hline \multicolumn{2}{|l|}{ Overall treatment time (weeks) } \\
\hline Median (range) & $6(4-17.3)$ \\
\hline Q1-Q3 & $5.3-8$ \\
\hline \multicolumn{2}{|l|}{$\begin{array}{l}\text { Weeks of treatment (minus GAP duration) "effective } \\
\text { treatment time" (weeks) }\end{array}$} \\
\hline Median (range) & $5.9(4.3-16.1)$ \\
\hline Q1-Q3 & $5.3-7$ \\
\hline \multicolumn{2}{|l|}{ Total dose to Pelvis (Gy) } \\
\hline Median (range) & $39.6(0.9-60)$ \\
\hline
\end{tabular}




\begin{tabular}{|cc|}
\hline Q1-Q3 & $30.6-45$ \\
N non missing observations & 1329 \\
Total dose on anal canal (Gy) & \\
Median (range) & $50.4(38.6-98)$ \\
Q1-Q3 & $50.4-59$ \\
& \\
$\leq 50.5 G y$ & $716(53.3)$ \\
$>50.5-\leq 55 G y$ & $169(12.6)$ \\
$>55-\leq 59 G y$ & $198(14.7)$ \\
$>59 G y-\leq 59.4 G y$ & $152(11.3)$ \\
$>59.4 G y$ & $108(8)$ \\
\hline
\end{tabular}

$*$ There were 5 aberrant values. 
Appendix A. Figure 3: Duration of follow up in the pooled analysis. Online only.

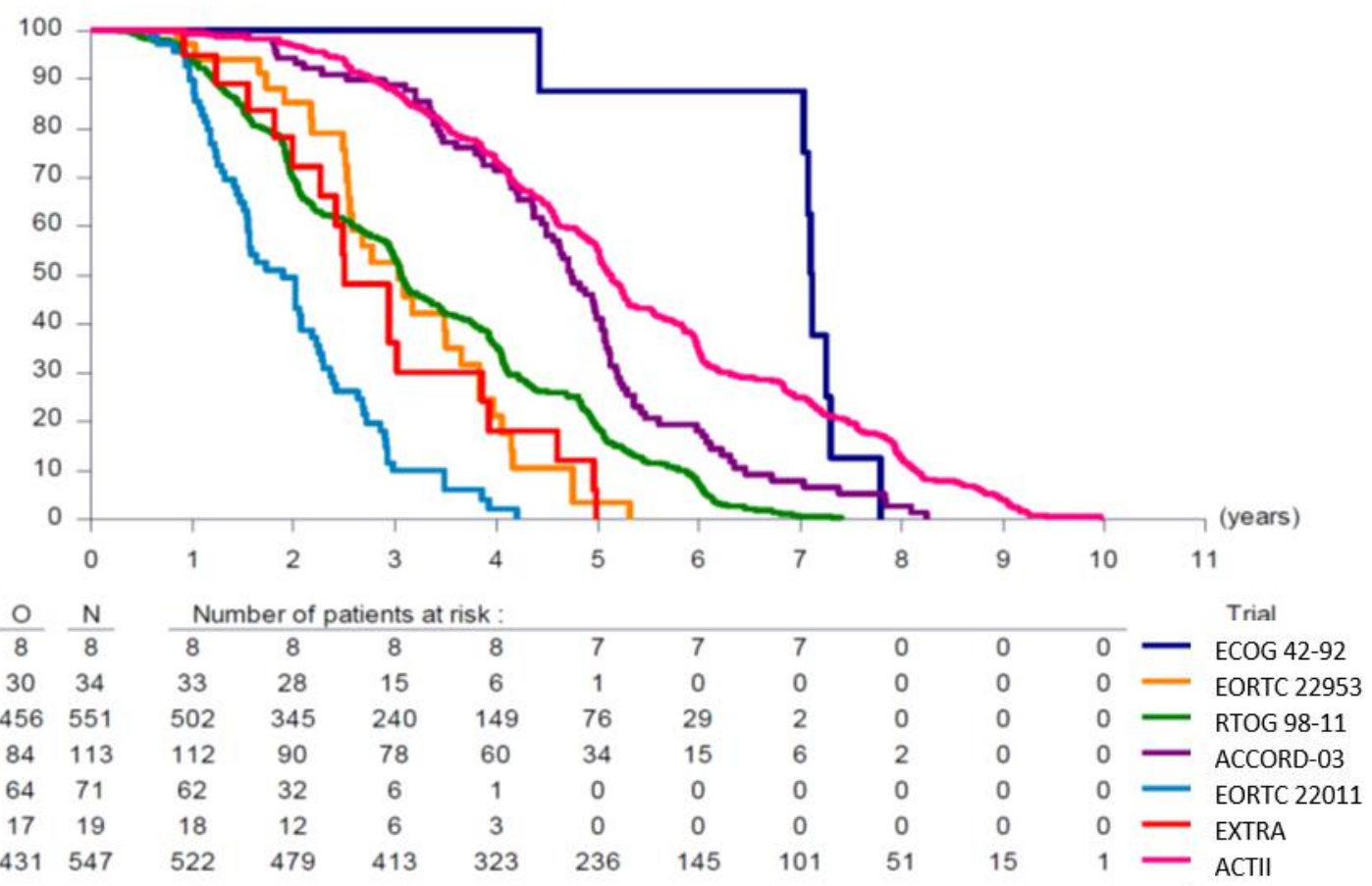


Figure 2. (a) Cumulative incidence of locoregional failure (b) Progression free survival and (c) Overall survival.

(a) Locoregional failure

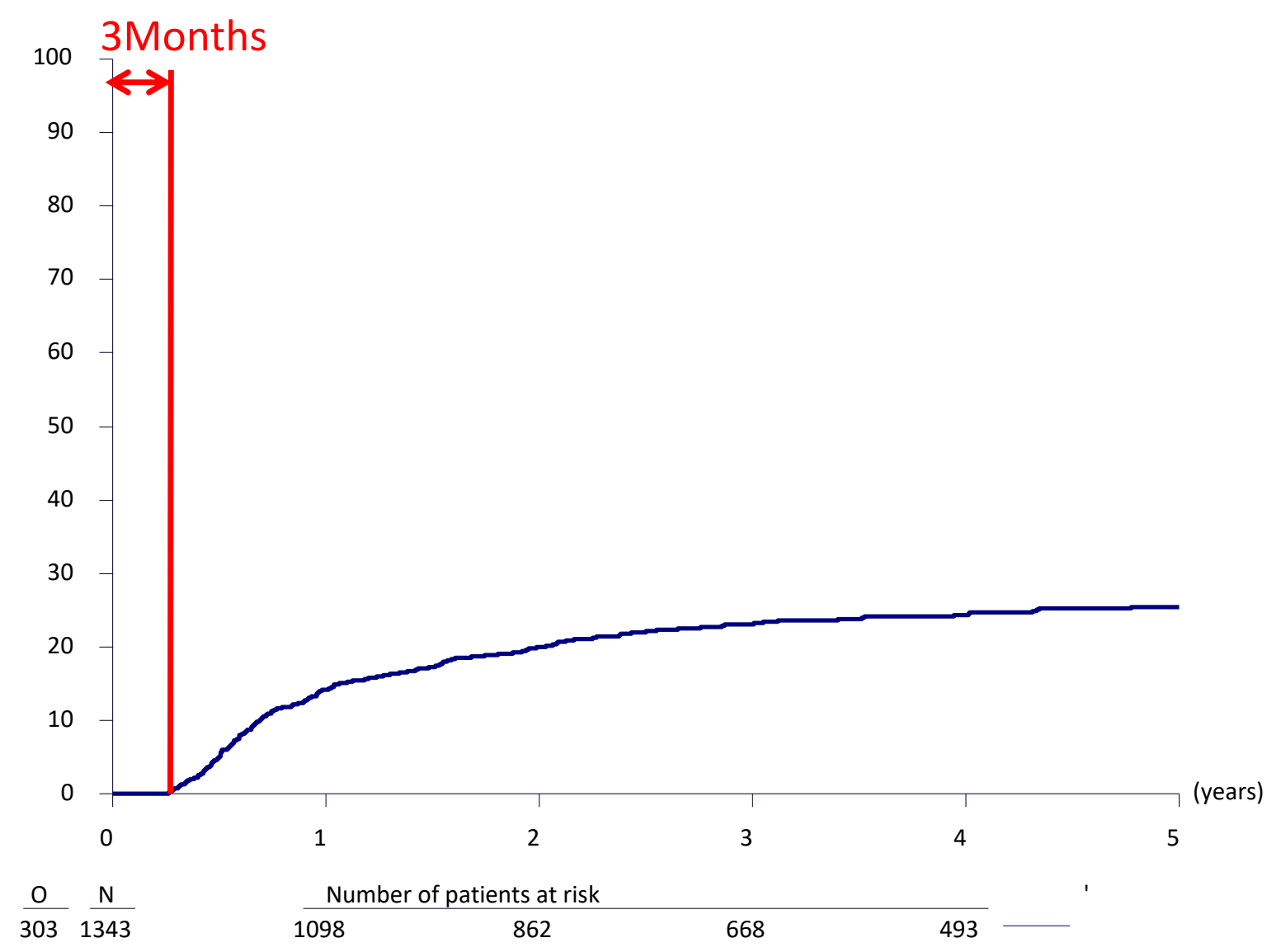


(b) Progression-free survival

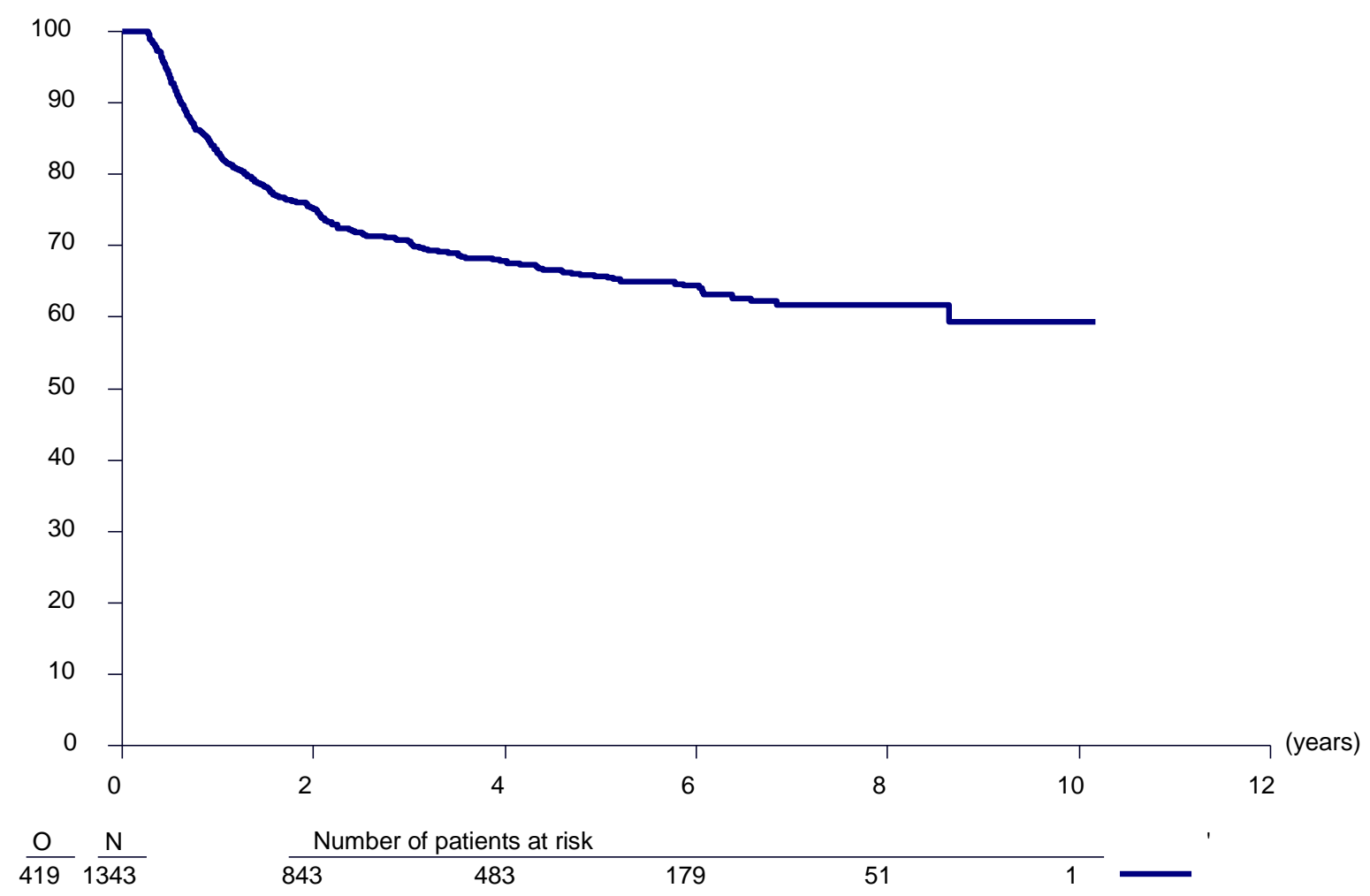


(c) Overall survival

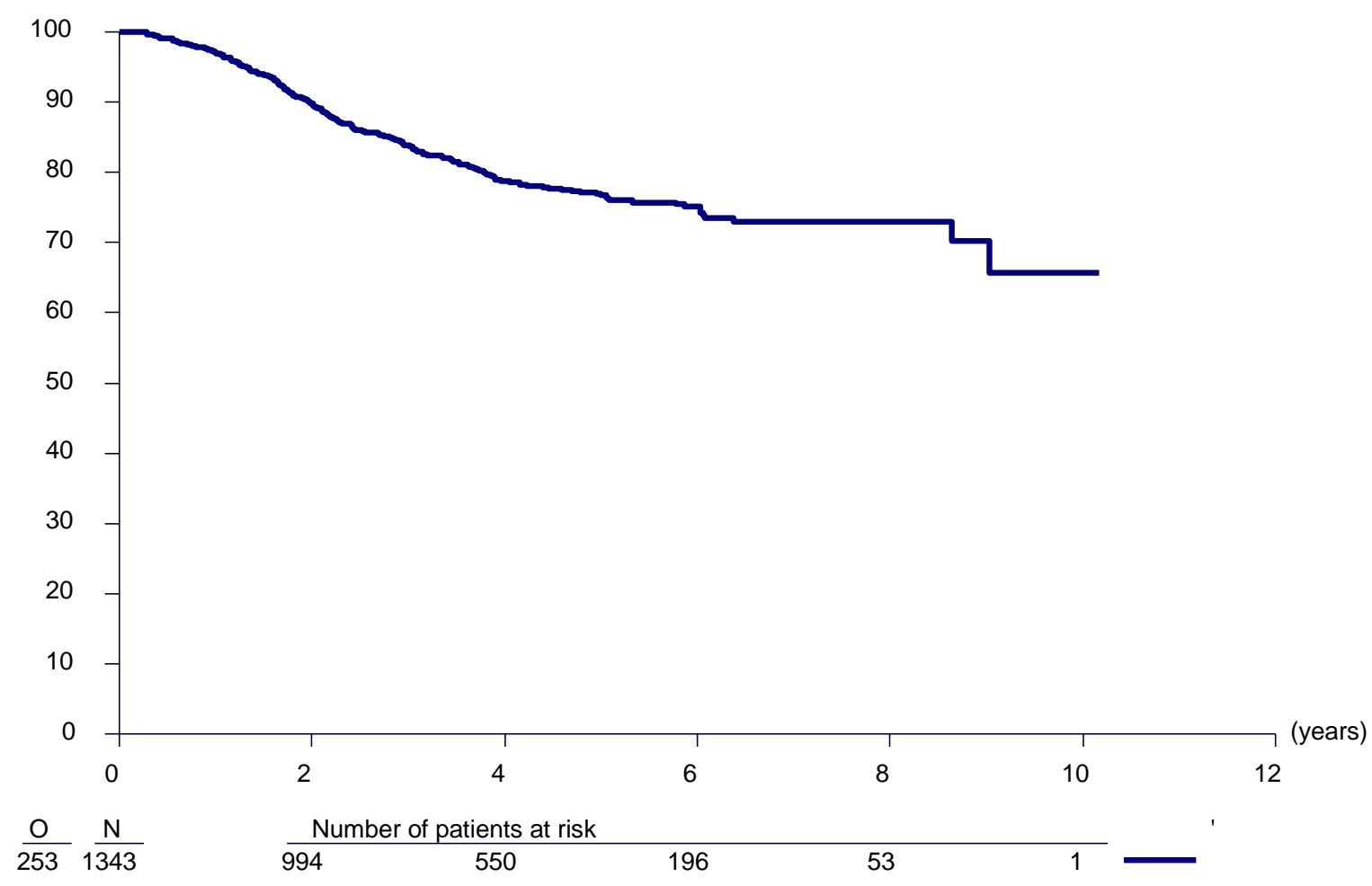


Appendix A. Table 2: Models of overall treatment time and dose of radiation therapy for

(a) Locoregional failure (b) Progression free survival (c) Overall survival and (d)

Treatment parameters by gender. Online only.

\section{(a) Locoregional failure}

\begin{tabular}{|c|c|c|c|c|c|c|c|}
\hline \multirow{3}{*}{$\begin{array}{l}\text { Overall treatment time } \\
\text { (weeks) }\end{array}$} & \multirow[b]{2}{*}{ Dose $\leq 50.5 \mathrm{G}$} & & \multirow{2}{*}{\begin{tabular}{|c|}
$H R$ \\
1.15
\end{tabular}} & \multicolumn{2}{|c|}{$\mathrm{HR} 95 \% \mathrm{Cl}$} & \multirow{2}{*}{$\begin{array}{c}P \\
0.065\end{array}$} & \multirow{2}{*}{$\begin{array}{c}\text { Best if } \\
\text { Time } \downarrow\end{array}$} \\
\hline & & & & 0.99 & 1.34 & & \\
\hline & Dose $50.51 \mathrm{C}$ & & 0.98 & 0.72 & 1.34 & 0.908 & \\
\hline \multirow[b]{2}{*}{$P=0.03(d f=5)$} & \multicolumn{2}{|c|}{ Dose $55.01 \mathrm{~Gy}-59 \mathrm{~Gy}$} & 1.23 & 1.04 & 1.45 & 0.017 & Time $\downarrow$ \\
\hline & & & & & & & \\
\hline & \multicolumn{2}{|c|}{ Dose $59.01 \mathrm{~Gy}$ - $59.4 \mathrm{~Gy}$} & 1.14 & 0.88 & 1.47 & 0.309 & \\
\hline & \multicolumn{2}{|c|}{ Dose $>59.4 \mathrm{~Gy}$} & 1.14 & 0.96 & 1.36 & 0.128 & Time $\downarrow$ \\
\hline Total dose on anal canal & \multicolumn{2}{|c|}{50.51 Gy - 55 Gy vs. $\leq 50.5$ Gy } & 2.00 & 0.20 & 19.79 & 0.552 & \\
\hline \multirow[t]{3}{*}{$P=0.937(d f=4)$} & \multicolumn{2}{|c|}{55.01 Gy - 59 Gy vs. $\leq 50.5$ Gy } & 0.68 & 0.14 & 3.40 & 0.643 & \\
\hline & \multicolumn{2}{|c|}{$59.01 \mathrm{~Gy}-59.4$ Gy vs. $\leq 50.5$ Gy } & 0.76 & 0.06 & 8.88 & 0.825 & \\
\hline & \multicolumn{2}{|c|}{$>59.4$ Gy vs. $\leq 50.5$ Gy } & 0.73 & 0.08 & 6.26 & 0.774 & \\
\hline \multirow{2}{*}{\multicolumn{3}{|c|}{$\begin{array}{l}\text { Age (years) } \\
P=0.234\end{array}$}} & 0.99 & 0.98 & 1.00 & 0.234 & \\
\hline & & & & & & & \\
\hline \multirow{8}{*}{$\begin{array}{l}\text { Tumor size (cm) in: } \\
P<0.001(d f=6)\end{array}$} & Anal margin & NO & 0.83 & 0.60 & 1.15 & 0.257 & \\
\hline & Anal margin & $N+$ ing- & 1.00 & & & & \\
\hline & Anal margin & $\mathrm{N}+$ ing+ & 0.96 & 0.73 & 1.26 & 0.761 & \\
\hline & Anal margin & $\mathrm{N}+$ ing? & 1.00 & & & & \\
\hline & Anal canal & No & 1.11 & 1.05 & 1.18 & 0.001 & Small \\
\hline & Anal canal & $\mathrm{N}+$ ing- & 1.19 & 1.06 & 1.34 & 0.004 & Small \\
\hline & Anal canal & $\mathrm{N}+$ ing+ & 1.22 & 1.09 & 1.38 & 0.001 & Small \\
\hline & Anal canal & $\mathrm{N}+$ ing? & 0.99 & 0.85 & 1.16 & 0.926 & \\
\hline \multirow{4}{*}{$\begin{array}{l}\text { N stage } \\
P=0.377(d f=3)\end{array}$} & \multirow{2}{*}{\multicolumn{2}{|c|}{$\mathrm{N}+$ ing- vs. NO }} & 0.94 & 0.44 & 2.04 & 0.883 & \\
\hline & & & 104 & 017 & & & \\
\hline & \multicolumn{2}{|c|}{$\mathrm{N}+$ ing+ vs. NO } & & & & & \\
\hline & \multicolumn{2}{|c|}{$\mathrm{N}+$ ing ? vs. NO } & 2.28 & 0.89 & 5.87 & 0.087 & \\
\hline $\begin{array}{l}\text { Tumor loc } \\
\mathrm{P}=0.07\end{array}$ & \multicolumn{2}{|c|}{ Anal canal vs. Anal margin } & 0.30 & 0.08 & 1.10 & 0.07 & \\
\hline $\begin{array}{l}\text { Gender } \\
P=0.045\end{array}$ & \multicolumn{2}{|c|}{ Female vs. Male } & 0.78 & 0.61 & 0.99 & 0.045 & Female* \\
\hline
\end{tabular}




\section{(b) Progression free survival}

\begin{tabular}{|c|c|c|c|c|c|c|c|}
\hline \multirow{3}{*}{$\begin{array}{l}\text { Overall treatment time } \\
\text { (weeks) }\end{array}$} & \multirow[b]{2}{*}{ Dose $\leq 50.5 \mathrm{G}$} & & \multirow{2}{*}{$\begin{array}{c}H R \\
1.15\end{array}$} & \multicolumn{2}{|c|}{$\mathrm{HR}$ 95\% Cl } & \multirow{2}{*}{$\begin{array}{c}P \\
0.031\end{array}$} & \multirow{2}{*}{$\begin{array}{l}\text { Best if } \\
\text { Time } \downarrow\end{array}$} \\
\hline & & & & 1.01 & 1.31 & & \\
\hline & Dose $50.51 \mathrm{G}$ & & 1.06 & 0.83 & 1.35 & 0.662 & \\
\hline \multirow{4}{*}{$P=0.025(d f=5)$} & Dose $55.01 \mathrm{G}$ & & 1.14 & 0.98 & 1.32 & 0.095 & \\
\hline & & & & & & & \\
\hline & Dose $59.01 \mathrm{G}$ & 4 Gy & 1.19 & 0.96 & 1.48 & 0.105 & \\
\hline & Dose $>59.4 \mathrm{G}$ & & 1.14 & 0.98 & 1.33 & 0.1 & \\
\hline Total dose on anal canal & $50.51 \mathrm{~Gy}-55$ & $\leq 50.5 \mathrm{~Gy}$ & 1.28 & 0.20 & 8.35 & 0.799 & \\
\hline \multirow[t]{3}{*}{$P=0.937(d f=4)$} & $55.01 \mathrm{~Gy}-59$ & $\leq 50.5 \mathrm{~Gy}$ & 1.32 & 0.32 & 5.36 & 0.7 & \\
\hline & $59.01 \mathrm{~Gy}-59$ & s. $\leq 50.5 \mathrm{~Gy}$ & 0.51 & 0.06 & 4.12 & 0.528 & \\
\hline & $>59.4$ Gy vs. & & 0.73 & 0.11 & 4.91 & 0.75 & \\
\hline Age (years) & & & 1.00 & 0.99 & 1.01 & 0.927 & \\
\hline \multicolumn{8}{|l|}{$P=0.927$} \\
\hline \multirow{6}{*}{$\begin{array}{l}\text { Tumor size }(\mathbf{c m}) \text { in: } \\
P<0.001(d f=6)\end{array}$} & Anal margin & No & 0.90 & 0.71 & 1.16 & 0.424 & \\
\hline & Anal margin & $\mathrm{N}+$ ing+ & 1.01 & 0.81 & 1.26 & 0.927 & \\
\hline & Anal canal & NO & 1.12 & 1.07 & 1.18 & $<0.001$ & Small \\
\hline & Anal canal & $\mathrm{N}+$ ing- & 1.16 & 1.04 & 1.29 & 0.006 & Small \\
\hline & Anal canal & $\mathrm{N}+$ ing+ & 1.19 & 1.07 & 1.32 & 0.001 & Small \\
\hline & Anal canal & $\mathrm{N}+$ ing? & 0.99 & 0.87 & 1.12 & 0.87 & \\
\hline \multirow{3}{*}{$\begin{array}{l}\text { N stage } \\
P=0.055(d f=3)\end{array}$} & $\mathrm{N}+$ ing- vs. $\mathrm{NC}$ & & 1.10 & 0.56 & 2.13 & 0.784 & \\
\hline & $\mathrm{N}+$ ing+ vs. $\mathrm{N}$ & & 1.42 & 0.73 & 2.78 & 0.305 & \\
\hline & $\mathrm{N}+$ vs. NO & & 2.79 & 1.31 & 5.94 & 0.008 & \\
\hline $\begin{array}{l}\text { Tumor loc } \\
\mathrm{P}=0.191\end{array}$ & Anal canal vs & nargin & 0.49 & 0.17 & 1.43 & 0.191 & \\
\hline $\begin{array}{l}\text { Gender } \\
\mathrm{P}<0.001\end{array}$ & Female vs. M & & 0.67 & 0.54 & 0.82 & 0.001 & Female \\
\hline
\end{tabular}




\section{(c) Overall survival}

\begin{tabular}{|c|c|c|c|c|c|c|c|}
\hline \multirow{3}{*}{$\begin{array}{l}\text { Overall treatment time } \\
\text { (weeks) }\end{array}$} & \multirow[b]{2}{*}{ Dose $\leq 50.5 \mathrm{G}$} & & \multirow{2}{*}{\begin{tabular}{|l|}
$H R$ \\
1.13
\end{tabular}} & \multicolumn{2}{|c|}{$\mathrm{HR} 95 \% \mathrm{Cl}$} & \multirow{2}{*}{$\begin{array}{c}P \\
0.159\end{array}$} & \multirow[t]{2}{*}{ Best if } \\
\hline & & & & 0.95 & 1.33 & & \\
\hline & Dose $50.51 \mathrm{G}$ & & 1.21 & 0.88 & 1.66 & 0.231 & \\
\hline \multirow{4}{*}{$P=0.026(d f=5)$} & Dose $55.01 \mathrm{G}$ & & 1.16 & 0.98 & 1.38 & 0.089 & Time $\downarrow$ \\
\hline & & & & & & & \\
\hline & Dose $59.01 \mathrm{G}$ & + Gy & 1.31 & 0.95 & 1.80 & 0.1 & \\
\hline & Dose $>59.4 \mathrm{G}$ & & 1.22 & 1.00 & 1.50 & 0.05 & Time $\downarrow$ \\
\hline Total dose on anal canal & $50.51 \mathrm{~Gy}-55$ & $\leq 50.5 \mathrm{~Gy}$ & 0.39 & 0.03 & 4.56 & 0.456 & \\
\hline \multirow[t]{3}{*}{$P=0.937(d f=4)$} & $55.01 \mathrm{~Gy}-59$ & $\leq 50.5 \mathrm{~Gy}$ & 1.03 & 0.19 & 5.56 & 0.976 & \\
\hline & $59.01 \mathrm{~Gy}-59$ & s. $\leq 50.5 \mathrm{~Gy}$ & 0.16 & 0.01 & 3.69 & 0.255 & \\
\hline & $>59.4$ Gy vs. & & 0.26 & 0.02 & 3.29 & 0.3 & \\
\hline Age (years) & & & 1.00 & 0.99 & 1.02 & 0.633 & \\
\hline \multicolumn{8}{|l|}{$P=0.639$} \\
\hline \multirow{6}{*}{$\begin{array}{l}\text { Tumor size }(\mathbf{c m}) \text { in: } \\
P=0.027(d f=6)\end{array}$} & Anal margin & NO & 0.99 & 0.75 & 1.31 & 0.956 & \\
\hline & Anal margin & $\mathrm{N}+$ ing+ & 1.11 & 0.87 & 1.42 & 0.384 & \\
\hline & Anal canal & No & 1.10 & 1.03 & 1.18 & 0.007 & Small \\
\hline & Anal canal & $\mathrm{N}+$ ing- & 1.14 & 1.00 & 1.29 & 0.043 & Small \\
\hline & Anal canal & $\mathrm{N}+$ ing+ & 1.12 & 0.96 & 1.31 & 0.164 & Small \\
\hline & Anal canal & $\mathrm{N}+$ ing? & 1.01 & 0.87 & 1.17 & 0.882 & \\
\hline \multirow{3}{*}{$\begin{array}{l}\text { N stage } \\
P=0.079(d f=3)\end{array}$} & $\mathrm{N}+$ ing- vs. $\mathrm{N}$ & & 1.08 & 0.46 & 2.54 & 0.859 & \\
\hline & $\mathrm{N}+$ ing+ vs. $\mathrm{N}$ & & 2.23 & 0.95 & 5.75 & 0.065 & \\
\hline & $\mathrm{N}+$ ing ? vs. & & 2.62 & 1.04 & 6.63 & 0.041 & \\
\hline $\begin{array}{l}\text { Tumor loc } \\
\mathrm{P}=0.954\end{array}$ & Anal canal vs & nargin & 1.04 & 0.28 & 3.84 & 0.954 & \\
\hline $\begin{array}{l}\text { Gender } \\
P<0.001\end{array}$ & Female vs. $\mathrm{M}$ & & 0.56 & 0.43 & 0.72 & $<0.001$ & Female \\
\hline
\end{tabular}




\section{d. Treatment parameters by gender}

\begin{tabular}{|c|c|c|}
\hline & \multicolumn{2}{|c|}{ Gender } \\
\hline & $\begin{array}{c}\text { Male } \\
(\mathrm{N}=449)\end{array}$ & $\begin{array}{l}\text { Female } \\
(\mathrm{N}=894)\end{array}$ \\
\hline \multicolumn{3}{|c|}{ Overall treatment time (days) including boost } \\
\hline Median (range) & $39(30-107)$ & $43(30-121)$ \\
\hline Q1-Q3 & $37-52$ & $37-57$ \\
\hline \multicolumn{3}{|c|}{ Total dose on anal canal (Gy) } \\
\hline Median (range) & $50.4(39.6-75)$ & $50.4(38.6-98)$ \\
\hline Q1-Q3 & $50.4-57.4$ & $50.4-59$ \\
\hline \multicolumn{3}{|c|}{ Effect of treatment being a woman } \\
\hline Median (range) & $5.6(4.3-15.3)$ & $6(4.3-16.1)$ \\
\hline Q1-Q3 & $5.3-6.6$ & $5.3-7$ \\
\hline \multicolumn{3}{|l|}{ Duration of the gap } \\
\hline Median (range) & $0(0-44)$ & $0(0-68)$ \\
\hline Q1-Q3 & $0-0$ & $0-0$ \\
\hline
\end{tabular}


Appendix A: Table 3: Locoregional failure model comparing doses of 50.4 Gy vs. 55-59 Gy without a Gap (N=977) (RTOG 98-11, ACT II and EXTRA) Online only.

\begin{tabular}{|c|c|c|c|c|c|c|c|}
\hline \multirow[b]{2}{*}{ Planned Dose anal canal } & & \multirow[b]{2}{*}{$55-59$ vs 50.4 Gy } & \multirow{2}{*}{$\begin{array}{c}H R \\
1.14\end{array}$} & \multicolumn{2}{|c|}{$\mathrm{HR} 95 \% \mathrm{Cl}$} & \multirow{2}{*}{$\begin{array}{c}\boldsymbol{P} \\
0.159\end{array}$} & \multirow{2}{*}{$\begin{array}{l}\text { Best if } \\
\text { Lower* }\end{array}$} \\
\hline & & & & 0.84 & 1.54 & & \\
\hline \multicolumn{8}{|l|}{$P=0.412$} \\
\hline Age (years) & & & 0.99 & 0.98 & 1.01 & 0.468 & \\
\hline \multicolumn{8}{|l|}{$P=0.468$} \\
\hline \multirow{8}{*}{$\begin{array}{l}\text { Tumor size }(\mathbf{c m}) \text { in: } \\
P=0.002(d f=4)\end{array}$} & Anal margin & No & 0.77 & 0.54 & 1.11 & 0.165 & \\
\hline & Anal margin & $\mathrm{N}+$ ing- & 1.00 & & & 0.384 & \\
\hline & Anal margin & $\mathrm{N}+$ ing+ & 0.99 & 0.74 & 1.31 & 0.921 & \\
\hline & Anal margin & $N+$ ing? & 1.00 & & & & \\
\hline & Anal canal or both & NO & 1.11 & 1.05 & 1.19 & 0.001 & Small \\
\hline & Anal canal or both & $N+$ ing- & 1.18 & 1.04 & 1.33 & 0.009 & Small \\
\hline & Anal canal or both & $\mathrm{N}+$ ing+ & 1.25 & 1.08 & 1.19 & 0.003 & Small \\
\hline & Anal canal or both & $\mathrm{N}+$ ing? & 1.01 & 0.86 & 2.97 & 0.542 & \\
\hline \multirow{3}{*}{$\begin{array}{l}\text { N stage } \\
P=0.333(d f=4)\end{array}$} & $\mathrm{N}+$ ing- & & 1.08 & 0.46 & 2.54 & 0.859 & \\
\hline & $\mathrm{N}+$ ing+ & & 2.23 & 0.95 & 5.75 & 0.065 & \\
\hline & $\mathrm{N}+$ ing? & & 2.62 & 1.04 & 6.63 & 0.041 & \\
\hline $\begin{array}{l}\text { Tumor localization } \\
P=0.033\end{array}$ & Anal canal or both & & 0.21 & 0.05 & 0.88 & 0.032 & Both \\
\hline $\begin{array}{l}\text { Gender } \\
P=0.574\end{array}$ & Female vs. Male & & 0.92 & 0.69 & 1.23 & 0.577 & Female \\
\hline
\end{tabular}


Appendix A: Table 4: Locoregional failure model: 3week vs 2week gap at 59.4Gy intended dose (EORTC studies and ACCORD-03) ). Online only.

\begin{tabular}{|c|c|c|c|c|c|c|c|}
\hline \multirow[b]{2}{*}{ Planned gap } & \multirow[b]{2}{*}{$21 \mathrm{~d}$ vs 14 days } & & \multirow{2}{*}{$\begin{array}{c}H R \\
1.37\end{array}$} & \multicolumn{2}{|c|}{$\mathrm{HR} 95 \% \mathrm{Cl}$} & \multirow{2}{*}{$\begin{array}{c}\boldsymbol{P} \\
0.245\end{array}$} & \multirow[t]{2}{*}{ Best if } \\
\hline & & & & 0.81 & 2.34 & & \\
\hline \multicolumn{8}{|l|}{$P=0.245$} \\
\hline Age (years) & & & 0.97 & 0.95 & 1.00 & 0.02 & Young \\
\hline \multicolumn{8}{|l|}{$P=0.02$} \\
\hline \multirow{3}{*}{$\begin{array}{l}\text { Tumor size }(\mathrm{cm}) \text { in: } \\
P=0.377(\mathrm{df}=4)\end{array}$} & Anal canal or both & NO & 1.19 & 0.93 & 1.53 & 0.173 & \\
\hline & Anal canal or both & $\mathrm{N}+$ ing- & 1.10 & 0.83 & 1.47 & 0.49 & \\
\hline & Anal canal or both & $\mathrm{N}+$ ing+ & 1.13 & 0.88 & 1.45 & 0.333 & \\
\hline \multirow{2}{*}{$\begin{array}{l}\text { N stage } \\
P=0.468\end{array}$} & $\mathrm{~N}+$ ing- & & 1.70 & 0.25 & 11.68 & 0.589 & \\
\hline & $\mathrm{N}+$ ing+ & & 3.21 & 0.50 & 20.55 & 0.218 & \\
\hline $\begin{array}{l}\text { Gender } \\
P=0.228\end{array}$ & Female vs. Male & & 0.71 & 0.41 & 1.23 & 0.228 & Female \\
\hline
\end{tabular}

Abbreviations: $\mathrm{N}+$ ing-: $\mathrm{N}+$ without inguinal invasion; $\mathrm{N}+\mathrm{ing}+\mathrm{N}+$ with inguinal invasion; $\mathrm{N}+\mathrm{ing}$ ?: $\mathrm{N}+$ with unknown inguinal status. 


\section{Appendix A: Table 5: 2 week gap vs no gap at (a) 55-59.4Gy intended dose and b) effective dose >56.5 and <60Gy (EORTC studies vs. RTOG 98-11). Online only.}

(a)

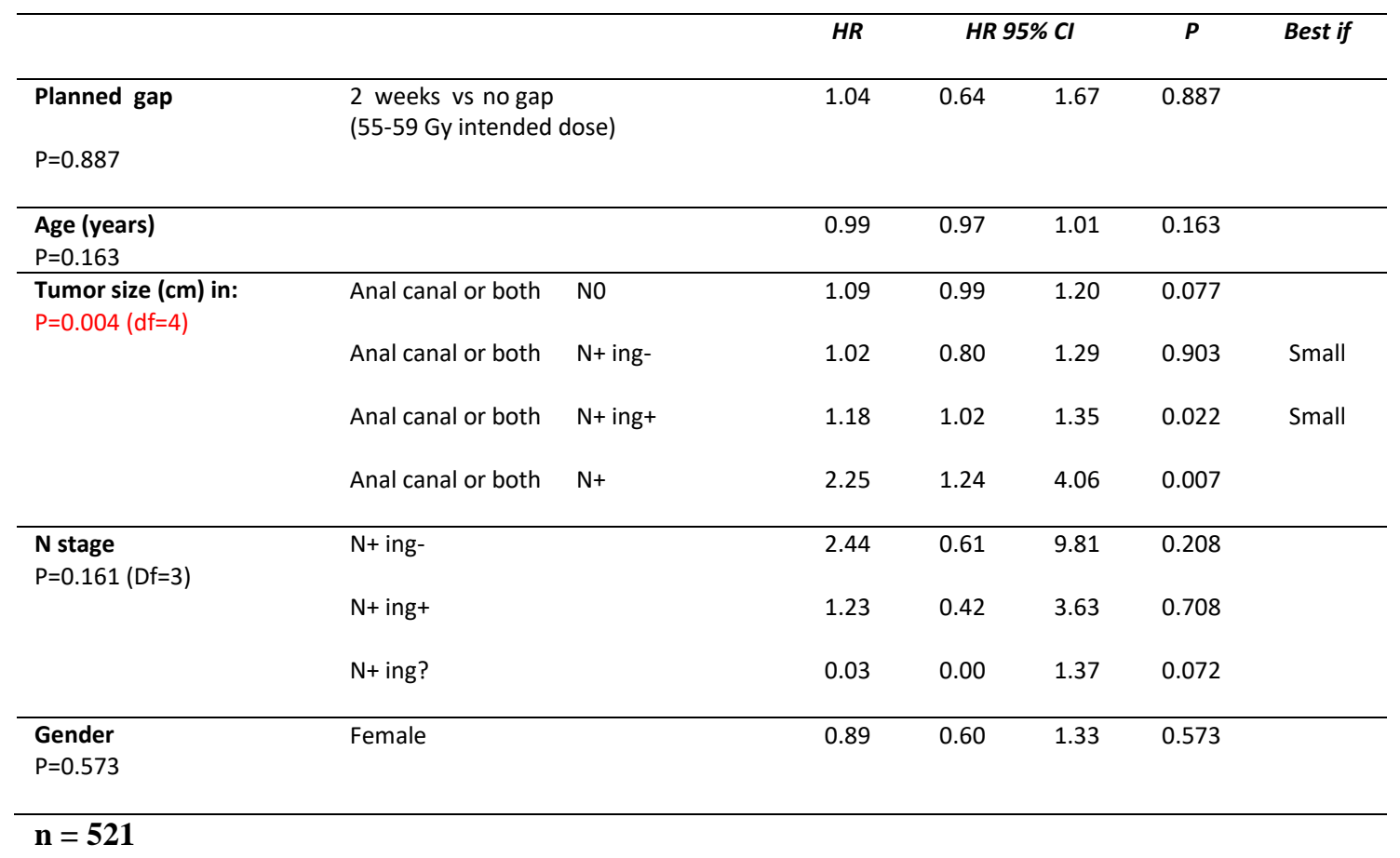

(b)

\begin{tabular}{|c|c|c|c|c|c|c|}
\hline \multirow[b]{2}{*}{ Planned gap } & \multirow[b]{2}{*}{$\begin{array}{l}2 \text { weeks vs no gap } \\
\text { (effective dose }>56.5 \text { and }<60 G y \text { ) }\end{array}$} & \multirow{2}{*}{$\begin{array}{c}H R \\
0.87\end{array}$} & \multicolumn{2}{|c|}{$\mathrm{HR} 95 \% \mathrm{Cl}$} & \multirow{2}{*}{$\begin{array}{c}P \\
0.559\end{array}$} & \multirow[t]{3}{*}{ Best if } \\
\hline & & & 0.52 & 1.47 & & \\
\hline \multicolumn{6}{|l|}{$P=0.559$} & \\
\hline Age (years) & & 0.99 & 0.97 & 1.01 & 0.163 & \\
\hline \multicolumn{7}{|l|}{$P=0.163$} \\
\hline $\begin{array}{l}\text { Tumor size }(\mathrm{cm}) \text { in: } \\
P=0.214\end{array}$ & & 1.06 & 0.97 & 1.17 & 0.214 & \\
\hline \multirow{3}{*}{$\begin{array}{l}\text { N stage } \\
P=0.064(D f=3)\end{array}$} & $\mathrm{N}+$ ing- & 1.58 & 0.87 & 2.87 & 0.130 & \\
\hline & $\mathrm{N}+$ ing+ & 2.15 & 1.20 & 3.84 & 0.01 & \\
\hline & $\mathrm{N}+$ ing? & 1.58 & 0.48 & 5.19 & 0.449 & \\
\hline Gender & Female & 0.79 & 0.49 & 1.28 & 0.339 & \\
\hline$P=0.339$ & & & & & & \\
\hline
\end{tabular}

$\mathrm{n}=\mathbf{2 1 4}$

Abbreviations: $\mathrm{N}+$ ing-: $\mathrm{N}+$ without inguinal invasion; $\mathrm{N}+\mathrm{ing}+\mathrm{N}+$ with inguinal invasion; $\mathrm{N}+\mathrm{ing}$ ?: $\mathrm{N}+$ with unknown inguinal status. 
Table 3. Late toxicities: (a) gastro-intestinal (b) skin or subcutaneous tissue and (c) genitourinary.

\begin{tabular}{|c|c|c|c|c|c|c|c|c|c|}
\hline (a) & $\begin{array}{l}\text { EORTC } \\
22861 \\
\\
N=110\end{array}$ & $\begin{array}{l}\text { ACT I } \\
N=577\end{array}$ & $\begin{array}{l}\text { RTOG } \\
87-04 \\
N=289\end{array}$ & $\begin{array}{l}\text { EORTC } \\
22953 \\
N=44\end{array}$ & $\begin{array}{l}\text { RTOG } 98- \\
11 N=638\end{array}$ & $\begin{array}{l}A C C-03 \text { (1st } \\
\text { tox) N=307 }\end{array}$ & $\begin{array}{l}\text { EORTC } \\
22011 \\
N=88\end{array}$ & $\begin{array}{l}\text { EXTRA } \\
N=31\end{array}$ & $\begin{array}{l}A C T \| \\
N=935\end{array}$ \\
\hline Any grade & $72(65.5)$ & & $\begin{array}{l}63 \\
(21.8)\end{array}$ & $37(84.1)$ & $155(24.3)$ & $242(78.8)$ & $39(44.3)$ & $\begin{array}{l}24 \\
(77.4)\end{array}$ & $\begin{array}{l}706 \\
(75.5)\end{array}$ \\
\hline Mild & $69(62.7)$ & & $\begin{array}{l}58 \\
(20.1)\end{array}$ & $37(84.1)$ & $140(21.9)$ & $184(59.9)$ & $39(44.3)$ & $\begin{array}{l}24 \\
(77.4)\end{array}$ & $\begin{array}{l}697 \\
(74.5)\end{array}$ \\
\hline Severe & $30(27.2)$ & $\begin{array}{l}180 \\
(31.2)\end{array}$ & $8(2.8)$ & $13(29.5)$ & $15(2.4)$ & $58(18.9)$ & $1(1.1)$ & $0(0)$ & $71(7.6)$ \\
\hline $\begin{array}{l}\text { Grade } \\
\text { ynknowen }\end{array}$ & $3(2.7)$ & $0(0)$ & $0(0)$ & $0(0)$ & $0(0)$ & $0(0)$ & $0(0)$ & $0(0)$ & $0(0)$ \\
\hline
\end{tabular}

\begin{tabular}{|c|c|c|c|c|c|c|c|}
\hline & EORTC 22861 & ACTI & RTOG 87-04 & EORTC 22953 & EORTC 22011 & EXTRA & ACT II \\
\hline & $N=110$ & $N=577$ & $N=289$ & $N=44$ & $N=88$ & $N=31$ & $N=935$ \\
\hline Any grade & $14(12.7)$ & & $15(5.2)$ & $29(65.9)$ & $22(25)$ & $3(9.7)$ & 298 (31.9) \\
\hline Mild & $5(4.5)$ & & $13(4.5)$ & $28(63.6)$ & $22(25)$ & $3(9.7)$ & $288(30.8)$ \\
\hline Severe & $4(3.6)$ & $39(6.8)$ & $2(0.7)$ & $18(40.9)$ & $1(1.1)$ & $0(0)$ & $23(2.5)$ \\
\hline Grade unknown & $5(4.5)$ & $0(0)$ & $0(0)$ & $0(0)$ & $0(0)$ & $0(0)$ & $0(0)$ \\
\hline
\end{tabular}




\section{$\underline{\text { Discussion }}$}

This meta-analysis of individual patient data from 10 trials evaluating results of anal cancer patients receiving combined modality treatment confirmed the effect of RT-related factors on patient outcomes. OTT and tumor size were found to have a significant impact on LRF, PFS and OS, while the effects of dose levels and gap duration were more difficult to interpret.

LRF was the predominant pattern of relapse, with a 5-year LRF rate in accordance with recent trials ${ }^{30-32}$. Shorter OTTs were significantly associated with less LRF, as were small tumor sizes for tumors of the anal canal and female gender. For patients receiving intermediate doses (55-59 Gy, RTOG 98-11) versus 50.4 Gy (ACT II and EXTRA), no major difference of LRF was observed between dose levels. Paradoxically, patients who received the lower dose seemed to have better outcomes. This may have not reached significance due to possible remaining biases in the meta-analysis (after adjusting for patient characteristics) and to differences between protocol guidelines. These findings support current guidelines from ESMO-ESSO-ESTRO guidelines which suggest no benefit in administering RT doses >50 Gy without a gap during combined modality treatment, especially for good responders ${ }^{33}$. The duration of the gap on LRF was assessed by comparing patients planned to receive 59.4 Gy with a 2 or a 3 week gap from the EORTC studies versus ACCORD-03 arms 1 and 3, finding that a 3 week gap could be potentially detrimental. The lack of a significant difference may be due to the small number of patients in this analysis. However, when a 2 week gap was compared to no gap for doses between 57 and 59.4 Gy (EORTC studies versus RTOG 98-11) there were no significant differences between groups. Our data suggests that if the gap is detrimental, it is for gaps $\geq 3$ weeks, which also increase the OTT (significantly associated with LRF). This may explain the lack of benefit in ACCORD-03 for doses $>59.4 \mathrm{~Gy}$, as a 3 week gap was used ${ }^{17}$. In 2011, Glynne- 
Jones et al. advocated to avoid "split course" treatments ${ }^{34}$. This was based on evidence that on one hand (TROG 99-02), if a gap was planned, it should be done as late as possible in the treatment course, and on the other hand, non-randomized retrospective data seems to indicate a worse outcome with gaps of $>38$ or $>63$ days $^{34-38}$.

With regards to survival rates, PFS at 5 years was similar to a recent phase II study evaluating the addition of Cetuximab to 5-FU-Cisplatin concurrent chemoradiotherapy, and approximately $10 \%$ lower than in two other recent studies ${ }^{30-32}$. Five-year OS $(76.7 \%)$ was also similar to the results of the Cetuximab association trial, and 4-7\% lower than the other two recent studies $^{30-32}$. Shorter OTTs, smaller tumors and female gender, again, were found to be significantly associated with a better PFS and OS. OTT is a known prognostic factor in other squamous cell carcinomas, such as cervical cancer, where every day $>52$ days causes a reduction of LC by $1 \%$, as well as in head and neck cancer ${ }^{39,}{ }^{40}$. Although there is a paucity of data on the characteristics of proliferation of anal cancer, they seem similar to cervical cancer, with a potential median doubling-time of 4.1 days $^{41}$. It is noteworthy, that clinical results of combined modality therapy in anal cancer show that OTT might have less of an impact as chemotherapy may increase the interval of growth delay of clonogenic cells ${ }^{42}$. An OTT $>41$ days was found to compromise 5-year LC, whether the treatment included a gap or not ${ }^{43}$. An analysis performed on pooled data from the RTOG 87-04 and 98-11 trials found a significant impact of OTT on local and LRF (in agreement with the present meta-analysis), colostomy failure and time to failure without a correlation with CFS or OS (conversely, it correlated with OS in the present metaanalysis $)^{44}$.

Considering the impact of OTT on outcomes of combined therapy for anal cancer, strategies have been developed to shorten OTT while attempting to reduce toxicity. IMRT and 
VMAT have been proven to be feasible and current results show less skin, hematological and gastro-intestinal toxicity with comparable outcomes to results from 3D-conformal RT treatments ${ }^{12-14,16,45}$. These results should be interpreted with caution. A recent analysis of the national Veterans Affairs database compared 779 patients receiving either IMRT or 3Dconformal $\mathrm{RT}^{15}$. Indeed, they found a decrease of treatment breaks, resulting in shorter OTT in patients receiving IMRT, but without significant improvement of severe gastro-intestinal or hematological toxicity. The authors hypothesize this may be due to incorrect planning or delivery, which highlights the need to follow international guidelines and homogenize contouring practices to improve these results, not only in terms of toxicity, but also in terms of outcomes $^{14,15,33,46}$. A single center study which reviewed 45 patients treated by $3 \mathrm{D}$-conformal RT or IMRT found OTT was an independent predictor of OS and PFS ${ }^{47}$. Additionally, simultaneous integrated boost during IMRT or VMAT treatment can considerably shorten OTT. A multicenter retrospective study evaluated 190 patients receiving either a simultaneous integrated boost (SIB) or a sequential boost for combined modality treatment for anal cancer ${ }^{48}$. With a median follow up of 34 and 31 months for each group, median OTT was significantly lower (43 vs. 60 days) in the SIB group, as was the cumulative incidence of colostomy ${ }^{13}$.

Toxicity results from this meta-analysis were difficult to interpret due to heterogeneous toxicity scoring and reporting. The descriptive data from the pooled analysis show more severe gastro-intestinal toxicity in the EORTC 22861 and EORTC 22953 trials, more severe skin toxicity in the EORTC 22953 trial and more severe genito-urinary toxicity in the EORTC 22953 and ACCORD-03 trials.

A limitation of this meta-analysis is that individual patient data from only 10 of the 13 identified trials was received. Possibly, data from the 3 remaining phase II trials (in total: 191 
patients) may have influenced the meta-analysis. Nevertheless, data from the large phase III trials were received and analyzed, which is a strength. For the sake of homogeneity (heterogeneous patient selection criteria, staging systems and capture of RT data), patient data from 3 of the early trials as well as $44 \%$ of the patients from the rest of the studies had to be excluded from the analysis. Also, the intrinsic design of the studies analyzed did not allow the dose and the gap duration to be evaluated separately. Approximately $25 \%$ of patients in the final analysis received neoadjuvant chemotherapy (patients from RTOG 98-11 and ACCORD-03), which might have caused an accelerated repopulation at the time of combined RT-doublet chemotherapy, eventually impacting the relevance of OTT in these patients ${ }^{8,17}$. Last, but not least, we were not able to stratify according to HPV status or smoking.

Ongoing trials may shed more light these questions, such as the PLATO protocol (ISRCTN88455282), integrating 3 trials: ACT3 for small tumors (phase II, non-randomized, local excision), ACT4 for intermediate-risk tumors (phase II, randomized, standard-dose 50.4 Gy vs. reduced-dose 41.4 Gy combined modality treatment) and ACT5 for locally advanced tumors (phase II/III, randomized, standard dose 53.2 Gy vs. 58.8 Gy and 61.6 Gy combined modality treatment) with the primary outcome of 3-year LRF. Thus, the question of dose-escalation is being tested in larger tumors, which is coherent with our results, as smaller tumors had better outcomes. A recent pooled analysis of two prospective trials including locally advanced anal cancer (tumors $>4 \mathrm{~cm}$ ) found better CFS with dose escalation ${ }^{49}$.

Treatment outcomes may not only benefit from changes in RT schemes, but also from changes in the drugs used for combined therapy. In the aforementioned study, although the addition of cetuximab to Cisplatin/5-FU decreased local failure rates, it came at the cost of increased toxicity ${ }^{32}$. Another study testing this association had to close prematurely due to 
serious adverse events ${ }^{50}$. Future directions might include combinations with immunotherapy, such as pembrolizumab ${ }^{51}$. Ongoing trials are investigating the role of immunotherapy in the adjuvant setting, EA2165: Nivolumab After Combined Modality Therapy in Treating Patients With High Risk Stage II-IIIB Anal Cancer (NCT03233711).

As MR-Linacs become more widely available, newer techniques such as MRI-guided RT are being evaluated. Online adaptive treatment strategies may be developed using this technology, considering the clear superiority of MRI imaging for soft tissues. This technique could allow real time tumor tracking, taking into account intra-fractional motion ${ }^{52}$. Daily adaptive re-planning would allow effective treatment while potentially reducing toxicity ${ }^{53}$.

Recent progress in the validation of a specific EORTC quality of life questionnaire for anal cancer will allow better assessment of toxicity in patients included in future trials ${ }^{54}$. Such patient-related outcomes are essential to provide more robust evidence on toxicity outcomes.

\section{Conclusions}

This meta-analysis suggests that for patients treated with a combination of external-beam RT with 2 chemotherapeutic drugs, a longer OTT is detrimental. Further analyses suggest that in the dose range of 50.4-59 Gy lower doses seem to be preferred. Treatment gaps longer than 2 weeks appear to be detrimental. When comparing a 2 week gap to no gap (dose range: 55-59.4 Gy), there is unlikely a difference in effect between a somewhat higher dose given with a gap and a somewhat lower dose given with no gap. Further prospective trials involving IMRT/VMAT techniques or even with MRI-guided RT may better define optimal OTT and dose escalation in schedules with no gap. 


\section{Reference List}

1. Nelson RA, Levine AM, Bernstein L, et al: Changing patterns of anal canal carcinoma in the United States. J Clin Oncol 31:1569-1575, 2013

2. Nelson VM, Bowen Benson III A: Epidemiology of Anal Canal Cancer. Surg Oncol Clin $26: 9-15,2017$

3. Papillon J, Mayer M, Montbarbon JM, et al: A new approach to the management of epidermoid carcinoma of the anal canal. Cancer 1830-1837, 1983

4. Ryan DP, Compton CC, Mayer RJ: Carcinoma of the anal canal. N Engl J Med 792-800, 2000

5. Lin D, Gold HT, Schreiber D, et al: Impact of socioeconomic status on survival for patients with anal cancer. Cancer 124:1791-1797, 2018

6. Bartelink BH, Roelofsen F, Eschwege F, et al: Concomitant Radiotherapy and Chemotherapy Is Superior to Radiotherapy Alone in the Treatment of Locally Advanced Anal Cancer: Results of a Phase III Randomized Trial of the European European Organization for Research and Treatment of Cancer Radiotherapy a. J Clin Oncol 15:2040-2049, 1997

7. Spithoff K, Cummings B, Jonker D, et al: Chemoradiotherapy for Squamous Cell Cancer of the Anal Canal: A Systematic Review. Clin Oncol 26:473-487, 2014

8. Ajani J a.: Fluorouracil, mitomycin, and radiotherapy vs. fluorouracil, cisplatin, and radiotherapy for carcinoma of the anal canal: a randomized controlled trial. Dis Colon Rectum $51: 1914-1921,2008$

9. James RD, Glynne-Jones R, Meadows HM, et al: Mitomycin or cisplatin chemoradiation with 
or without maintenance chemotherapy for treatment of squamous-cell carcinoma of the anus (ACT II): a randomised, phase 3, open-label, 2x2 factorial trial. Lancet Oncol 14:516-524, 2013

10. Lim F, Glynne-Jones R: Chemotherapy/chemoradiation in anal cancer: A systematic review. Cancer Treat Rev 37:520-532, 2011

11. Kachnic L, Winter K, Myerson R, et al: NRG Oncology/RTOG 0529: Long-Term Outcomes of Dose-Painted Intensity Modulated Radiation Therapy, 5-Fluorouracil, and Mitomycin-C in Anal Canal Cancer. Int J Radiat Oncol Biol Phys 99:S64-S65, 2017

12. Call JA, Prendergast BM, Jensen LG, et al: Intensity-modulated Radiation Therapy for Anal Cancer Results From a Multi-Institutional Retrospective Cohort Study. Am J Clin Oncol 39:812,2016

13. Franco P, Arcadipane F, Ragona R, et al: Volumetric modulated arc therapy (VMAT) in the combined modality treatment of anal cancer patients. Br J Radiol , 2016

14. Klausner G, Blais E, Jumeau R, et al: Management of locally advanced anal canal carcinoma with intensity-modulated radiotherapy and concurrent chemotherapy. Med Oncol 35:134, 2018

15. Bryant AK, Huynh-Le M-P, Simpson DR, et al: Clinical Investigation Intensity Modulated Radiation Therapy Versus Conventional Radiation for Anal Cancer in the Veterans Affairs System Radiation Oncology. Int J Radiat Oncol Biol Phys 102:109-115, 2018

16. De Bari B, Lestrade L, Franzetti-Pellanda A, et al: Modern intensity-modulated radiotherapy with image guidance allows low toxicity rates and good local control in chemoradiotherapy for anal cancer patients. J Cancer Res Clin Oncol 144:781-789, 2018

17. Peiffert D, Tournier-Rangeard L, Gérard JP, et al: Induction chemotherapy and dose 
intensification of the radiation boost in locally advanced anal canal carcinoma: Final analysis of the randomized UNICANCER ACCORD 03 trial. J Clin Oncol 30:1941-1948, 2012

18. Bosset JF, Roelofsen F, Morgan DAL, et al: Shortened irradiation scheme, continuous infusion of 5-fluorouracil and fractionation of mitomycin $\mathrm{C}$ in locally advanced anal carcinomas. Results of a phase II study of the European Organization for Research and Treatment of Cancer Radiotherapy and Gastro. Eur J Cancer 39:45-51, 2003

19. Matzinger O, Roelofsen F, Mineur L, et al: Mitomycin C with continuous fluorouracil or with cisplatin in combination with radiotherapy for locally advanced anal cancer (European Organisation for Research and Treatment of Cancer phase II study 22011-40014) for the EORTC Radiation Oncology and Gastr. Eur J Cancer 45:2782-2791, 2009

20. UKCCCR Anal Cancer Trial Working Party U: Epidermoid anal cancer: Results from the UKCCCR randomised trial of radiotherapy alone versus radiotherapy, 5-fluorouracil, and mitomycin: UKCCCR Anal Cancer Trial Working Party. UK Co-ordinating Committee on Cancer Research. UKCCCR Anal Cancer Trial Work. Lancet 348:1049-1054, 1996

21. Northover J, Glynne-Jones R, Sebag-Montefiore D, et al: Chemoradiation for the treatment of epidermoid anal cancer: 13-year follow-up of the first randomised UKCCCR Anal Cancer Trial (ACT I). Br J Cancer 102:1123-1128, 2010

22. Glynne-Jones R, Meadows H, Wan S, et al: Extra—a multicenter phase II study of chemoradiation using a 5 day per week oral regimen of Capecitabine and intravenous Mitomycin C in anal cancer. Int J Radiat Oncol Biol Phys 72:119-126, 2008

23. Flam M, John M, Pajak TF, et al: Role of Mitomycin in Combination With Fluorouracil and 
Radiotherapy, and of Salvage Chemoradiation in the Definitive Nonsurgical Treatment of Epidermoid Carcinoma of the Anal Canal: Results of a Phase III Randomized Intergroup Study. J Clin Oncol 14:2527-39, 1996

24. Konski A, Garcia M, John M, et al: Evaluation of planned treatment breaks during radiation therapy for anal cancer: update of RTOG 92-08. Int J Radiat Oncol Biol Phys 72:114-118, 2008

25. Ajani JA, Winter KA, Gunderson LL, et al: US intergroup anal carcinoma trial: Tumor diameter predicts for colostomy. J Clin Oncol 27:1116-1121, 2009

26. Peiffert D, Giovannini M, Ducreux M, et al: High-l-dose radiation therapy and neoadjuvant plus concomitant chemotherapy with 5-fluorouracil and cisplatin in patients with locally advanced squamous-cell anal canal cancer: Final results of a phase II study. Ann Oncol Oncol $12: 397-404,2001$

27. Chakravarthy AB, Catalano PJ, Martenson JA, et al: Long-term follow-up of a phase II trial of high-dose radiation with concurrent 5-Fluorouracil and Cisplatin in patients with anal cancer (ECOG E4292). Int J Radiat Oncol Biol Phys 81:e607-e613, 2011

28. Meropol NJ, Niedzwiecki D, Shank B, et al: Induction therapy for poor-prognosis anal canal carcinoma: A phase II study of the Cancer and Leukemia Group B (CALGB 9281). J Clin Oncol 26:3229-3234, 2008

29. Lin DY, Wei LJ, Ying Z: Checking the Cox Model with Cumulative Sums of MartingaleBased Residuals. Biometrika 80:557-572, 1993

30. Delhorme J-B, Antoni D, Mak KS, et al: Treatment that follows guidelines closely dramatically improves overall survival of patients with anal canal and margin cancers. Crit Rev 
Oncol / Hematol 101:131-138, 2016

31. Hosni A, Han K, Le LW, et al: The ongoing challenge of large anal cancers: prospective long term outcomes of intensity-modulated radiation therapy with concurrent chemotherapy.

Oncotarget 9:20439-20450, 2018

32. Garg MK, Zhao F, Sparano JA, et al: Cetuximab Plus Chemoradiotherapy in

Immunocompetent Patients With Anal Carcinoma: A Phase II Eastern Cooperative Oncology

Group-American College of Radiology Imaging Network Cancer Research Group Trial (E3205).

J Clin Oncol 35:718-726, 2017

33. Glynne-Jones R, Nilsson PJ, Aschele C, et al: Anal cancer : ESMO-ESSO-ESTRO clinical practice guidelines for diagnosis, treatment and follow-up *. Eur J Surg Oncol 40:1165-1176, 2014

34. Glynne-Jones R, Sebag-Montefiore D, Adams R, et al: Mind the gap' - the impact of variations in the duration of the treatment gap and overall treatment time in the first UK anal cancer trial (ACT I). Int J Radiat Oncol Biol Phys 81:1488-1494, 2011

35. Matthews J, on behalf of TROG 99.02 participants -: Early anal canal carcinoma — the Trans-Tasman Radiation Onocology Group (TROG) experience in TROG 99.02 study, in 55th Annual Scientific Meeting of the Royal Australian and New Zealand College of Radiologists. 2005, p A3

36. Weber DC, Kurtz JM, Allal AS: The impact of gap duration on local control in anal canal carcinoma treated by split-course radiotherapy and concomitant chemotherapy. Int J Radiat Oncol Biol Phys 50:675-680, 2001 
37. Deniaud-Alexandre E, Touboul E, Tiret E, et al: Results of definitive irradiation in a series of 305 epidermoid carcinomas of the anal canal. Int J Radiat Oncol Biol Phys 56:1259-1273, 2003

38. Peiffert D, Bey P, Pernot M, et al: Conservative treatment by irradiation of epidermoid cancers of the anal canal: prognostic factors of tumoral control and complications. Int J Radiat Oncol Biol Phys 37:313-324, 1997

39. Eun Lee J, Jae Huh S, on Park W, et al: Radical radiotherapy for locally advanced cancer of uterine cervix. Cancer Res Treat 36:222-227, 2004

40. Hendry JH, Bentzen SM, Dale RG, et al: A Modelled Comparison of The Effects of Using Different Ways to Compensate for Missed Treatment Days in Radiotherapy. Clin Oncol 8:297307, 1996

41. Wong CS, Tsang RW, Cummings BJ, et al: Proliferation parameters in epidermoid carcinomas of the anal canal. Radiother Oncol 349-353, 2000

42. Cummings BJ, Keane TJ, O'sullivan B, et al: Epidermoid anal cancer: treatment by radiation alone or by radiation and sfluorouracil with and without Mitomycin C. Radiat Oncol Biol Phys $21: 1115-1125,1991$

43. Graf R, Wust P, Hildebrandt B, et al: Clinical study impact of overall treatment time on local control of anal cancer treated with radiochemotherapy. Oncology 65:14-22, 2003

44. Ben-Josef E, Moughan J, Ajani JA, et al: Impact of Overall Treatment Time on Survival and Local Control in Patients With Anal Cancer : A Pooled Data Analysis of Radiation Therapy Oncology Group Trials 87-04 and 98-11. J Clin Oncol 28:5061-5066, 2010

45. Kachnic LA, Winter K, Myerson RJ, et al: Clinical Investigation: Gastrointestinal Cancer 
RTOG 0529: A Phase 2 Evaluation of Dose-Painted Intensity Modulated Radiation Therapy in Combination With 5-Fluorouracil and Mitomycin-C for the Reduction of Acute Morbidity in Carcinoma of the Anal Canal Ra. Int J Radiat Oncol Biol Phys 86:27-33, 2013

46. Rouard N, Peiffert D, Rio E, et al: Intensity-modulated radiation therapy of anal squamous cell carcinoma: Relationship between delineation quality and regional recurrence. Radiother Oncol 131:93-100, 2019

47. Bazan JG, Hara W, Hsu A, et al: Intensity-modulated radiation therapy versus conventional radiation therapy for squamous cell carcinoma of the anal canal. Cancer 117:3342-3351, 2011

48. Franco P, Bari B De, Arcadipane F, et al: Comparing simultaneous integrated boost vs sequential boost in anal cancer patients: results of a retrospective observational study. Radiat Oncol 1-8, 2018

49. Faivre J-C, Peiffert D, Vendrely V, et al: Prognostic factors of colostomy free survival in patients presenting with locally advanced anal canal carcinoma: A pooled analysis of two prospective trials (KANAL 2 and ACCORD 03). Radiother Oncol , 2018

50. Levy A, Azria D, Pignon J-P, et al: Low response rate after cetuximab combined with conventional chemoradiotherapy in patients with locally advanced anal cancer: Long-term results of the UNICANCER ACCORD 16 phase II trial, 2015

51. Ott PA, Piha-Paul SA, Munster P, et al: Safety and antitumor activity of the anti-PD-1 antibody pembrolizumab in patients with recurrent carcinoma of the anal canal. Ann Oncol 1036-1041, 2017

52. Masson I, Delpon G, Vendrely V: Revue générale Apport de la radiothérapie guidée par 
l'image et repositionnement du patient dans le cancer anorectal Image-guided radiotherapy contribution and patient setup for anorectal cancer treatment. Cancer/Radiothérapie 22:622-630, 2018

53. Glynne-jones R, Tan D, Hughes R, et al: Squamous-cell carcinoma of the anus: progress in radiotherapy treatment. Nat Publ Gr 13:447-459, 2016

54. Sodergren SC, Johnson CD, Gilbert A, et al: EORTC QLQ-ANL27 Phase I-III development of the EORTC QLQ-ANL27, a health-related quality of life questionnaire for anal cancer.

Radiother Oncol 126:222-228, 2018 